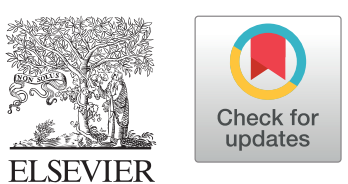

ELSEVIER

\title{
Review
}

\section{The Canadian Women's Heart Health Alliance Atlas on the Epidemiology, Diagnosis, and Management of Cardiovascular Disease in Women - Chapter 4: Sex- and Gender-Unique Disparities: CVD Across the Lifespan of a Woman}

\author{
Sharon L. Mulvagh, MD, FRCPC, FACC, FASE, FAHA, ${ }^{\text {a,b }}$ Kerri-Anne Mullen, PhD, MSc, \\ Kara A. Nerenberg, MD, MSc, ${ }^{d}$ Amy A. Kirkham, PhD, P.Kin, ATTH, \\ Courtney R. Green, PhD, MSc, ${ }^{f}$ Abida R. Dhukai, NP(Adult), MN, PhD(c), ${ }^{g}$ \\ Jasmine Grewal, MD, FRCPC, ${ }^{\text {h }}$ Marsha Hardy, MSW, RSW, \\ Paula J. Harvey, BMBS, PhD, FRACP, ${ }^{j}$ Sofia B. Ahmed, MD, MMSc, FRCPC, ${ }^{\mathrm{d}}$ \\ Donna Hart, BA, RSW, ${ }^{i}$ Anna L.E. Levinsson, PhD, ${ }^{k}$ \\ Monica Parry, MEd, MSc, NP-Adult, PhD, CCN(C), ${ }^{g}$ Heather J.A. Foulds, PhD, \\ Christine Pacheco, MD, MSc, FRCPC, ${ }^{\mathrm{m}}$ Sandra M. Dumanski, MD, FRCPC, ${ }^{\mathrm{d}}$
} Graeme Smith, MD, PhD, FRCSC, ${ }^{\mathrm{n}}$ and Colleen M. Norris, PhD, MSc, BScN, FAHA, FCAHS ${ }^{o, p}$

${ }^{a}$ Division of Cardiology, Dalhousie University, Halifax, Nova Scotia, Canada; ${ }^{b}$ Department of Cardiovascular Medicine, Mayo Clinic, Rochester, Minnesota, USA; 'Division of Cardiac Prevention and Rehabilitation, University of Ottawa Heart Institute, Ottawa, Ontario, Canada; ${ }^{2}$ Department of Medicine, University of Calgary, Calgary, Alberta, Canada; ${ }^{e}$ Faculty of Kinesiology and Physical Education, University of Toronto, Toronto, Ontario, Canada; ${ }^{f}$ The Society of Obstetricians and Gynaecologists of Canada, Ottawa, Ontario, Canada; ${ }^{g}$ Lawrence S. Bloomberg Faculty of Nursing, University of Toronto, Toronto, Ontario, Canada; ${ }^{h}$ Division of Cardiology, University of British Columbia, Vancouver, British Columbia, Canada; ${ }^{i}$ Canadian Women's Heart Health Alliance, Ottawa, Ontario, Canada; ${ }^{j}$ Women's College Research Institute and Division of Cardiology, Department of Medicine, Women's College Hospital, University of Toronto, Toronto, Ontario, Canada; ${ }^{k}$ Montreal Heart Institute; Beaulieu-Saucier Université de Montréal Pharmacogenomics Centre; Faculty of Medicine, Université de Montréal, Montréal, Quebec, Canada; 'College of Kinesiology, University of Saskatchewan, Saskatoon, Saskatchewan, Canada; ${ }^{m}$ Hôpital Pierre-Boucher, Centre Hospitalier de l'Université de Montréal (CHUM), Université de Montréal, Montreal, Québec, Canada, ${ }^{n}$ Department of Obstetrics and Gynecology, Kingston Health Sciences Centre, Queen's University, Kingston, Ontario, Canada; ${ }^{\circ}$ Faculty of Nursing, University of Alberta, Edmonton, Alberta, Canada; ${ }^{p}$ Cardiovascular Health and Stroke Strategic Clinical Network, Alberta Health Services, Edmonton, Alberta, Canada

\section{ABSTRACT}

Women have unique sex- and gender-related risk factors for cardiovascular disease (CVD) that can present or evolve over their lifespan. Pregnancy-associated conditions, polycystic ovarian syndrome, and menopause can increase a woman's risk of CVD. Women are at greater

\section{RÉSUMÉ}

Les femmes présentent des facteurs de risque de maladies cardiovasculaires (MCV) uniques, liés au sexe et au genre, qui peuvent se manifester ou évoluer tout au long de leur vie. Les troubles médicaux associés à la grossesse, le syndrome des ovaires polykystiques et la
Received for publication January 15, 2021. Accepted September 13, 2021.

Ethics Statement: The research reported has adhered to the relevant ethical guidelines.

Corresponding author: Dr Sharon L. Mulvagh, 1796 Summer St, Room 2148.5, Halifax, Nova Scotia B3H 3A7, Canada. Tel.: +1-902-473-7383; fax: 902-473-2434.

E-mail: Sharon.Mulvagh@nshealth.ca

See page 125 for disclosure information.
Women have unique risk factors for cardiovascular (CV) disease (CVD) related to aspects of female reproductive biology over their lifespan, including pregnancy-associated conditions, polycystic ovarian syndrome (PCOS), and menopause. ${ }^{1}$ Women are also at greater risk for autoimmune rheumatic disorders, which play a role in predisposition and pathogenesis of CVD; further, differential effects of traditional atherosclerotic CVD risk factors have been observed such that 
risk for autoimmune rheumatic disorders, which play a role in the predisposition and pathogenesis of CVD. The influence of traditional CVD risk factors (eg, smoking, hypertension, diabetes, obesity, physical inactivity, depression, anxiety, and family history) is greater in women than men. Finally, there are sex differences in the response to treatments for CVD risk and comorbid disease processes. In this Atlas chapter we review sex- and gender-unique CVD risk factors that can occur across a woman's lifespan, with the aim to reduce knowledge gaps and guide the development of optimal strategies for awareness and treatment. ménopause peuvent augmenter le risque de MCV chez une femme. Les femmes sont plus exposées aux troubles rhumatologiques autoimmuns, qui jouent un rôle dans la prédisposition et dans la pathogenèse des MCV. L'influence des facteurs de risque traditionnels pour les MCV (par exemple, le tabagisme, l'hypertension, le diabète, l'obésité, la sédentarité, la dépression, l'anxiété et les antécédents familiaux) est plus importante chez les femmes que chez les hommes. Enfin, il existe des différences entre les sexes dans la réponse aux traitements du risque de MCV et des processus pathologiques comorbides. Dans ce chapitre de l'Atlas, nous passons en revue les facteurs de risque de MCV propres au sexe et au genre qui peuvent survenir tout au long de la vie d'une femme, dans le but de réduire les lacunes dans les connaissances et d'orienter l'élaboration de stratégies optimales de sensibilisation et de traitement.

across the menarche groups were statistically significant according to province of residence, household income, and family type. Early and late menarche have been shown to increase the risk of CVD among women. ${ }^{4,6}$ Hispanic and black women experience an earlier age at menarche than white women. ${ }^{8-10}$ In one multicentre cohort study $(\mathrm{n}=648)$ a 4.5 times greater risk of major adverse cardiac events among women with menarche at 10 years of age and younger, and a 2.5 times greater risk of major adverse cardiac events for women with menarche at 15 years and older, compared with those with menarche at 12 years of age was reported. ${ }^{4}$ There are likely multiple mechanisms that explain the association between age at menarche and CVD. For example, women who experience early menarche have been reported to have higher adult body mass index (BMI), in part because of reduced adult height; increased BMI is independently associated with CVD as well as CVD risk factors. ${ }^{11,12}$ Later menarche has been linked to PCOS and might be associated with hypercortisolism and estrogen deficiency. ${ }^{4}$

Menstruation. The characteristics of a woman's menstruation and the changes that occur over the menstrual cycle have important implications in the assessment of CVD risk factors, manifestations, and treatment. Menstrual cycle irregularity might be a marker of metabolic abnormalities predisposing women to an increased risk of CVD and of CVD risk factors, such as diabetes mellitus. ${ }^{5,13}$ Furthermore, CVD risk factor measurement including cholesterol, C-reactive protein (CRP), glucose, and insulin can vary throughout the menstrual cycle. ${ }^{14}$ As a result, the proportion of women identified with CVD risk factors might vary depending on the menstrual phase of evaluation. ${ }^{\text {4,15 }}$ For total cholesterol, the midfollicular phase is recommended for measurement to reduce false negative results. Standardization or timing of measurements to menstrual cycle phase for markers of CRP and insulin sensitivity should be considered to reduce overall variability. ${ }^{14}$ Interestingly, the menstrual cycle has been shown to affect cardiac autonomic modulation, which decreases during the luteal phase of menstruation, with observed increases in incidence of arrhythmias. ${ }^{15}$

Contraception. Estrogen-based contraceptives, including implants, injections, patches, vaginal rings, and oral contraceptives have all been reported to increase a woman's risk of 
Table 1. Summary of existing guidelines, recommendations, and position statements concerning the management of cardiovascular risk and disease in relation to other sex- and gender-unique health conditions

\begin{tabular}{|c|c|c|}
\hline Condition & Document/guideline & Organization \\
\hline$\overline{\text { Contraceptive use }}$ & $\begin{array}{l}\text { - U.S. Medical Eligibility Criteria for Contraceptive Use } \\
\text { - Canadian Contraception Consensus Part } 4 \text { of } 4 \text { : } \\
\text { Combined Hormonal Contraception }\end{array}$ & $\begin{array}{l}\text { - Centers for Disease Control and Prevention } \\
\text { - The Society of Obstetricians and Gynaecologists of } \\
\text { Canada }\end{array}$ \\
\hline Pregnancy & $\begin{array}{l}\text { - } 2018 \text { Guidelines for the Management of Hypertension } \\
\text { in Pregnancy } \\
\text { - Cardiovascular Diseases During Pregnancy Guidelines } \\
\text { - Pregnancy and Heart Disease }\end{array}$ & $\begin{array}{l}\text { - Hypertension Canada }{ }^{31,227} \\
\text { - European Society of Cardiology } \\
\text { - The American College of Obstetricians and } \\
\text { Gynecologists }\end{array}$ \\
\hline Polycystic ovarian syndrome & $\begin{array}{l}\text { - Recommendations From the International Evidence- } \\
\text { Based Guideline for the Assessment and Management } \\
\text { of Polycystic Ovary Syndrome }\end{array}$ & $\begin{array}{l}\text { - The International Polycystic Ovarian Syndrome } \\
\text { Network }^{53}\end{array}$ \\
\hline Menopause & $\begin{array}{l}\text { - Chapter } 2 \text { Cardiovascular Disease } \\
\text { - } 2017 \text { Therapy Position Statement } \\
\text { - Hormone Therapy and Heart Disease } \\
\text { - } 2016 \text { Recommendations on Women's Midlife Health } \\
\text { and Menopause Hormone Therapy } \\
\text { - Menopause Transition and CVD Risk: } 2020 \text { Scientific } \\
\text { Statement }\end{array}$ & $\begin{array}{l}\text { - Society of Obstetrics and Gynecology of Canada } \\
\text { - The North American Menopause Society } \\
\text { - The American College of Obstetrics and Gynecology } \\
\text { - The International Menopause Society } \\
\text { - The American Heart Association }\end{array}$ \\
\hline Autoimmune rheumatic diseases & $\begin{array}{l}\text { - Chronic Pain, Diclofenac and Cardiovascular Risk: } \\
\text { Management Algorithm } \\
\text { - Clinical Practice Guidelines }\end{array}$ & $\begin{array}{l}\text { - The Canadian Rheumatology Association } \\
\text { - The American College of Rheumatology } \\
\text { - T24 }\end{array}$ \\
\hline Depression & $\begin{array}{l}\text { - Screening and Management of Depression in Patients } \\
\text { With Cardiovascular Disease: State-of-the-Art Review }\end{array}$ & - The American College of Cardiology ${ }^{196}$ \\
\hline Chronic kidney disease & $\begin{array}{l}\text { - Kidney Disease Improving Global Outcomes Guide- } \\
\text { lines (Sex-Specific Recommendations Under } \\
\text { Development) }\end{array}$ & - Kidney Disease Improving Global Outcomes ${ }^{225}$ \\
\hline Breast cancer & $\begin{array}{l}\text { - Guidelines for Evaluation and Management of Car- } \\
\text { diovascular Complications of Cancer Therapy } \\
\text { - Expert Consensus for Multimodality Imaging Evalua- } \\
\text { tion of Adult Patients During and After Cancer } \\
\text { Therapy } \\
\text { - Compounding Risk and Protection Model }\end{array}$ & $\begin{array}{l}\text { - Canadian Cardiovascular Society } \\
\text { - The American Society of Echocardiography/European } \\
\text { Association of Cardiovascular Imaging } \\
\text { - University of Alberta }\end{array}$ \\
\hline
\end{tabular}

arterial and venous thrombosis. ${ }^{16}$ Despite their reliability in preventing pregnancies, combined oral contraceptive (COC) therapy has been reported to increase the risk of arterial thrombosis that might result in $\mathrm{CV}$ events including myocardial infarction (MI) or stroke. ${ }^{16}$ CVD risk is further compounded with COC use among women older than 35 years of age: current smoking (10-fold increased risk of MI and threefold increased risk of stroke); the presence of poorly controlled hypertension (threefold risk of MI and stroke, and 15-fold risk of hemorrhagic stroke); or, a history of hypertension in pregnancy (increased risk of $\mathrm{MI}$ and venous thromboembolic events). ${ }^{17}$ Moreover, the risk of CVD depends on the type of progesterone and the dosage of estrogen used, with the safest oral form of hormonal contraception being that which contains levonorgestrel and $30 \mu \mathrm{g}$ of estrogen. ${ }^{18}$

Women who present with contraceptive needs must have individualized CVD risk assessment as part of the shared decision-making to determine the optimal contraceptive method. In women older than 35 years of age with numerous $\mathrm{CV}$ risk factors, or those with established ischemic heart disease, congestive heart failure, or cerebrovascular conditions, COCs are generally contraindicated, and the recommendation is for progestogen-only contraception, or, preferably, nonhormonal methods. ${ }^{16,19}$ Finally, in clinical practice particular attention should be paid to women with metabolic syndrome (MetS) or PCOS, who, in addition to their increased CV risk, might require long-term use of contraceptives, with careful monitoring of metabolic effects, and use of alternative nonhormonal contraceptive methods as needed. ${ }^{20,21}$

\section{Pregnancy-associated risks}

Pregnancy poses a physiologic stress on the CV system as it undergoes structural and hemodynamic changes to accommodate the increase in blood volume and hence cardiac output. By 20 weeks' gestation, cardiac output can increase to $>45 \%$ and stroke volume to $>25 \%$ of prepregnancy values. Each typically plateau after 20 weeks but remain elevated until delivery. ${ }^{22}$ Heart rate increases steadily to $>20 \%$ pregestation values, and peaks in the third trimester. ${ }^{23}$ These normal physiologic changes of pregnancy can uncover or intensify prepregnancy cardiac conditions (eg, congenital and valvular heart disease, preexisting cardiomyopathies, including cancer treatmentrelated cardiotoxicity) or result in new cardiac conditions (eg, arrhythmias, peripartum cardiomyopathy, aortic dissection, and pregnancy-associated MI, including spontaneous coronary artery dissection). In Canada, cardiac diseases affect 4.7 per 100,000 deliveries and is the most common diagnosis associated with maternal mortality during pregnancy and in the postpartum period. ${ }^{24}$ These adverse outcomes are even higher among women aged older than 40 years, with obesity, and of certain ethnic populations in Canada.

A prospective study of Canadian women with preexisting CVD showed that $50 \%$ of serious cardiac events experienced during pregnancy (eg, cardiac arrest or death, MI, urgent cardiac intervention, and serious arrhythmias) were preventable. $^{25}$ Much of this morbidity and mortality might be avoidable through: optimization of cardiac health before conception, management during pregnancy and postpartum by an experienced interdisciplinary team (eg, cardiology, 


\section{CANADIAN WOMEN'S HEART HEALTH ALLIANCE ATLAS}

Epidemiology, Diagnosis, and Management of Cardiovascular Disease in Women

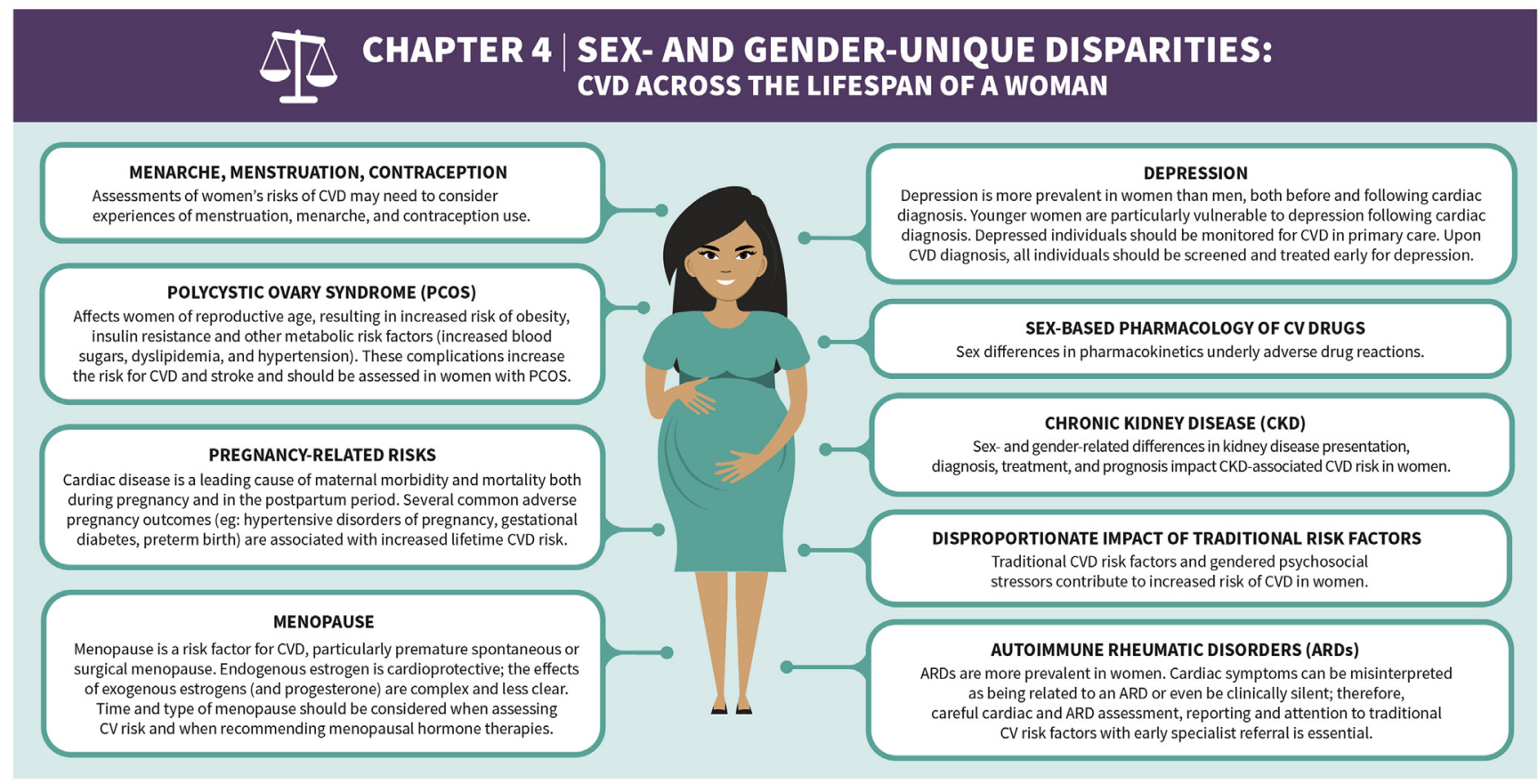

Figure 1. Summary of sex- and gender-unique conditions and factors that contribute to an increase in cardiovascular (CV) disease (CVD) risk for women across the lifespan.

maternal fetal medicine, obstetrics, and internal medicine), and use of health systems-level interventions that identify women at risk for preventable adverse outcomes (eg, the California Toolkit for Cardiac Disease in Pregnancy and Postpartum $\left.{ }^{26}\right)$. Further, individualized patient risk assessment using validated tools (eg, Cardiac Disease in Pregnancy [CARPREG] I or II, ${ }^{27}$ Modified World Health Organization classification of maternal $\mathrm{CV}$ risk $^{28}$ ) might aid women with known cardiac conditions in planning their pregnancy.

Finally, emerging epidemiologic data show that common reproductive complications such as hypertensive disorders of pregnancy, gestational diabetes mellitus (GDM), preterm birth, abruption, and infertility (in total, occurring in up to $20 \%$ of pregnancies in Canada) are independent, sex-specific risk factors associated with marked increases in the risk of future CVD (eg, premature atherosclerotic disease, arrhythmia, and heart failure). ${ }^{29}$ The recent recognition of the importance of the pregnancy and reproductive period in the CV health of women across their lifetime has led to recent emergence of the multidisciplinary field of "cardio-obstetrics," including expertise from cardiology and obstetrics within a team approach to enable the optimal management of CVDs and complications during pregnancy. ${ }^{30}$

Unique considerations of clinical presentation during pregnancy and the postpartum period. An important clinical challenge during pregnancy and the postpartum period is the differentiation between common symptoms of pregnancy (eg, benign dyspnea of pregnancy) and symptoms caused by acute or worsening CVD. Although clinicians generally rely on the physical examination, it is important to note that several laboratory tests (eg, troponin and B-type natriuretic peptide), imaging tests (eg, echocardiogram, radiograph, magnetic resonance imaging, computed tomography), as well as electrocardiogram, Holter monitors, and stress tests, can be done safely in pregnancy to guide diagnosis and management without serious harms to the fetus. Interpretation of test results, however, must recognize that cutoff values for normal results during pregnancy might be different than nonpregnant reference values.

Unique management considerations of CVD during pregnancy. Many common therapies for the treatment and prevention of CVD (eg, aspirin, $\beta$-blockers) can be safely used in pregnancy and lactation without adverse effects to the offspring. ${ }^{31,32}$ Knowledge of specific classes of medications associated with fetal harms that are generally avoided during pregnancy (eg, angiotensin-converting enzyme inhibitors, angiotensin II receptor blockers) should be noted. ${ }^{33}$ Individualized specialized interdisciplinary counselling and shared decision-making about medication safety during pregnancy and lactation is important with the recognition that clinical decision-making is centred on ensuring maternal well-being. 
Current state of preconception-to-postpartum clinical care and research in Canada. At present, most preconception-to-postpartum clinical care for women with CVD, including the postpartum care of women after hypertensive disorders of pregnancy or GDM, occurs in interdisciplinary tertiary care clinics across Canada, depending on local resources. Through the Canadian Adult Congenital Heart Network (www.cachnet.org) and the Canadian PostPregnancy Network (www.canadianpostpregnancynetwork. ca), researchers are leading the development of guidelines for clinical care of women from preconception to postpartum.

\section{Polycystic ovary syndrome}

PCOS is an endocrine disorder affecting 2.2\%-26.7\% of women of reproductive ages (15-45 years old). ${ }^{34,35}$ The prevalence is similar across ethnic groups. ${ }^{36}$ PCOS is a "syndrome" that affects the ovaries and ovulation and its 3 main features are: cysts in the ovaries; higher than normal levels of androgens with lower levels of estrogen, progesterone, folliclestimulating hormone, and luteinizing hormone; and, irregular or skipped menstrual cycles. It is believed that PCOS stems from factors including genetics (PCOS runs in families), insulin resistance (because of the preponderance of women with PCOS being obese), and increased levels of inflammation. PCOS is characterized by a greater tendency to obesity, ${ }^{37}$ central or visceral adiposity, ${ }^{37}$ and higher rates and degrees of hyperinsulinemia, insulin resistance, increased blood sugars, dyslipidemia, and hypertension. ${ }^{38-42}$ Women with PCOS also report higher levels of depression and anxiety. ${ }^{43}$ Insulin resistance and the resulting hyperinsulinemia ${ }^{38}$ contribute to the pathophysiology of metabolic complications in PCOS, including MetS, ${ }^{44,45}$ (dyslipidemia, ${ }^{46,47}$ impaired glucose tolerance ${ }^{48}$ ), type 2 diabetes mellitus, ${ }^{48}$ and obstructive sleep apnea. ${ }^{49,50}$ An increased mineralocorticoid effector mechanism has been observed in patients with PCOS, with elevated aldosterone levels and aldosterone to plasma renin activity ratios, ${ }^{51}$ potentially contributing to elevated blood pressure (BP). These unfavourable metabolic and physiologic complications increase CV risk and women with PCOS are more likely to have increased coronary artery calcium scores and increased carotid intima-media thickness. ${ }^{52}$

PCOS diagnosis is made from a combination of history, physical, laboratory, and imaging findings, which must include 2 of 3 of the following: high androgen levels (blood tests), irregular menstrual cycles (history consistent with irregular cycles, heavier than normal flow), and cysts in the ovaries (pelvic exam, ultrasound). ${ }^{53}$ Treatment for PCOS starts with health behaviour modifications including weight loss, diet, and exercise. Hormonal (estrogen and progestin) medications in the form of oral contraceptives, patches, or vaginal rings are used to restore normal hormonal balance, regulate ovulation, and control symptoms. Pharmacologic therapy with metformin has been found useful in symptom and weight management. In a meta-analyses of 12 randomized controlled trials, metformin, when used in addition to health behaviour modifications, was associated with lower BMI, less subcutaneous adipose tissue, and increased number of menstrual cycles at 6 months compared with health behaviour modifications and placebo. ${ }^{54}$ However, there were no differences in other anthropometric, metabolic (lipids and BP), reproductive, and psychological outcomes after 6 months between lifestyle with metformin vs lifestyle with placebo. To address the mineralocorticoid effector mechanism in PCOS, spironolactone has been used to counteract hyperandrogenism, improve $\mathrm{BP}$, and reduce future $\mathrm{CV}$ risk. ${ }^{5}$

\section{Menopause}

Menopause is the permanent cessation of menstruation and is a retrospective diagnosis defined after 12 months of amenorrhea. Median age for natural menopause is 51.4 years in North American Caucasian women, but there are notable ethnic and regional variations. Menopause before the age of 45 years is abnormal, and termed "premature" if younger than 40 years, and "early" if occurring between 40 and 45 years of age; it might be natural (because of primary or secondary ovarian insufficiency) or surgical (after bilateral oophorectomy). Natural menopause results in cessation of ovarian estrogen (primarily $17 \beta$-estradiol) production and elevated follicle-stimulating hormone concentrations, whereas the ovary continues to synthesize and secrete testosterone. Surgical menopause leads to loss of ovarian estrogen and testosterone production. $^{56}$

CVD and menopause. During their reproductive years, women are at lower risk of CVD than age-matched men. This CV "advantage" disappears after menopause. ${ }^{57}$ A history of frequent menopause-associated vasomotor symptoms (hot flashes and night sweats) has been associated with increased CV risk ${ }^{58}$; although a recent pooled analysis suggested that severity and timing (occurrence before or after menopause), rather than frequency, were associated with increased CVD risk. ${ }^{59}$ Data have been conflicting as to whether the type of menopause (natural vs surgical) affects CV risk, but it has long been recognized that the timing of menopause is associated with CV risk. Early (age 40-45 years), and especially premature (age younger than 40 years), menopause are associated with significant increases in morbidity and mortality from ischemic heart disease and ischemic stroke. ${ }^{56,60,61}$ In a recent cohort study that included 144,260 postmenopausal women, premature menopause, compared with no premature menopause, was associated with a significant increase in risk for a composite CVD outcome that included coronary artery disease $(\mathrm{CAD})$, heart failure, aortic stenosis, mitral regurgitation, atrial fibrillation, ischemic stroke, peripheral artery disease, and venous thromboembolism. ${ }^{62}$ For natural premature menopause, the hazard ratio was 1.36; for surgical premature menopause, the hazard ratio was 1.87 , both after adjustment for conventional CVD risk factors and use of menopausal hormone therapy (MHT). ${ }^{62}$ In a provocative further analysis of this database, a marker of accelerated atherosclerosis, clonal hematopoiesis of indeterminate potential (CHIP) was explored, and showed that premature menopause, especially natural premature menopause, was independently associated with CHIP among postmenopausal women. ${ }^{63}$ These findings suggested that natural premature menopause might represent a risk signal for latent genomic instability and predilection to develop CHIP and CHIP-associated CVD. The general recommendation by the North American Menopause Society for women with premature or early menopause (surgical or natural due to primary ovarian failure) is for early initiation of 
MHT (estrogen, with endometrial protection if the uterus is preserved) to be taken to the average age of natural menopause because of benefits observed in studies for atherosclerosis and CVD, cognition, and dementia. ${ }^{64}$

Specific CV preventive guidance was provided in the latest (2018) American College of Cardiology/American Heart Association update on guidelines for blood cholesterol management, recognizing premature menopause as a CVD riskenhancing factor favouring statin therapy initiation. ${ }^{65}$

The extent to which CVD risk factors across the menopause explain racial/ethnic differences in subclinical vascular disease in late midlife women is not well documented, but was explored in a multiethnic cohort subset of the Study of Women's Health Across the Nation including 1357 women, with a mean age of 60 years, and free of clinical CVD. ${ }^{66,67}$ Although race/ethnicity differences in subclinical CVD in late midlife women were identified, with thicker carotid walls in black women, wider arterial diameter in Chinese women, and less carotid plaque in black and Hispanic women compared with white women, the investigators reported that CVD risk factor associations with subclinical vascular measures did not vary according to race/ ethnicity except for high-density lipoprotein (HDL) cholesterol on common carotid artery intima-media thickness, wherein an inverse association between HDL cholesterol and common carotid artery intima-media thickness was observed in Chinese and Hispanic but not in white or black women. ${ }^{66}$

To date, the adverse effects of menopause on $\mathrm{CV}$ health have been largely attributed to hypoestrogenemia, as in primary ovarian insufficiency. ${ }^{57,68}$ These effects include evolution to an atherogenic cardiometabolic profile with increases in total cholesterol, low-density lipoprotein (LDL) cholesterol, and lipoprotein (a) $[\mathrm{Lp}(\mathrm{a})]$, and decreased HDL cholesterol, impaired glucose tolerance, elevated BP, and transition to an android adipose tissue distribution (increased central obesity). Additional noncardiometabolic effects include impaired bioactivity of nitric oxide, endothelial dysfunction, perturbation in autonomic function, activation of the reninangiotensin system, increased oxidative stress, altered mitochondrial function, and changes in inflammatory, coagulation, and fibrinolytic cascades. ${ }^{68}$ These effects in target tissues depend, at least in part, on the type and density of estrogen receptors (ERs; ER- $\alpha$, ER- $\beta$, and G protein-coupled estrogen receptor 1 ) and possibly the relative ratios of estrogens/androgens rather than estrogen(s) in isolation. ${ }^{69}$

Menopausal hormone therapy. The role of MHT in CV health and disease risk remains controversial and complex, influenced by factors that include age at menopause and time since menopause, referred to as the "timing hypothesis," as well as interactions with a preexisting atherosclerotic vascular substrate. ${ }^{70,71}$ Of additional importance are the MHT characteristics including hormonal formulation, dose, route of estrogen administration (eg, transdermal, oral, vaginal), whether with or without progesterone (unopposed vs combined estrogen and progesterone), and mode of delivery (cyclical or continuous). ${ }^{5,57,60}$ Evidence for CV effects of MHT has accrued and evolved over the past several decades. $^{60,72}$ Large observational studies and meta-analyses published in the 1980s suggested MHT prevented CVD and lowered all-cause mortality.
However, subsequent data from multiple clinical trials, meta-analyses, and post hoc reanalyses have shown contradicting and sometimes conflicting results regarding the role of MHT for prevention of CVD events. ${ }^{73-81}$ The general conclusions are that: (1) there is no role for MHT in secondary prevention of CVD; indeed, established atherosclerotic CVD is a contraindication to $\mathrm{MHT}^{76}$; (2) there is no clear indication for MHT in the primary prevention of CVD, except in the clinical situation of premature menopause; and (3) in the absence of contraindications, MHT can be used if administered early (within 10 years of menopause, and age $<60$ years old), primarily for vasomotor and and genitourinary indications.

\section{Summary}

Consideration of sex, hormonal status, and pregnancy history must all be included in the CV risk assessment, and diagnosis and treatment of women with CVD. Menstruation onset and characteristics, hypertensive or diabetic pregnancy complications, and menopausal timing and treatments are all contributory to $\mathrm{CV}$ health and/or disease. An awareness of increased CV risk in women with hypertensive and/or diabetic pregnancy complications, or premature menopause enables inclusion in routine $\mathrm{CV}$ risk assessments with appropriate interventions, and intensified assessments and management of traditional risk factors to improve long-term CV outcomes in affected women. Hormonal influences on metabolic and vascular effects might be cardioprotective or diseasepromoting, depending on temporal factors, concentration, and proportionality, and whether endogenous or exogenous exposure. The effects of exogenous estrogens (and progesterone) are complex and controversial, influenced by pharmacological and individual patient characteristics. There is currently no evidence to support the use of exogenous MHT for the specific purpose of primary or secondary $\mathrm{CV}$ risk prevention in postmenopausal women, except primary CV risk prevention in those with natural or surgical premature or early menopause.

\section{Sex, Gender, and the Disproportionate Effect of "Traditional" CV Risk Factors}

Sex and gender differences exist in the prevalence and effects of traditional CVD risk factors, including smoking, diabetes, hypertension, hyperlipidemia, obesity, sedentary behaviour, stress, depression and family history of CVD. ${ }^{82}$ Moreover, recent data indicate that, from a gender perspective, women face considerable barriers to access care and are less likely to be treated for their cardiac disease or predisposing conditions, or be prescribed CV preventive medications, compared with men. ${ }^{83,84}$

Astonishingly, these modifiable risk factors account for up to $94 \%$ of the population-attributable risks of MI among women. ${ }^{85}$

\section{Smoking and hypertension}

Among women, smoking is the single most important preventable cause of CVD, particularly among women younger than 55 years, increasing their risk sevenfold. ${ }^{86}$ There is a $25 \%$ increased risk in CAD conferred by cigarette 
smoking among women 45 years and older, compared with men. ${ }^{87}$ Hypertension is the most prevalent modifiable risk factor for CVD morbidity and mortality in men and women, and markedly increases in severity with age in women, especially those older than 65 years of age, such that the prevalence of hypertension in postmenopausal women is higher than in men. ${ }^{88}$ However, a recent large population study showed a sexual dimorphism in BP trajectories, with onset of elevation in women as early as the third decade in life, a steeper increase persisting with age, and setting the stage for later-life CVDs that frequently present differently in women vs men. ${ }^{89}$ Yet more women than men with high BP remain undiagnosed, and even in those taking antihypertensive medications, hypertension has been reported to be less well controlled in women than in men ${ }^{90}$; a myriad of reasons for this have been suggested including the effect of medication side effects or cost on compliance, lack of health care provider knowledge, and gender bias in treatments. ${ }^{91-93}$ An additive interaction between current smoking and hypertension in women on the risk of coronary heart disease (CHD) has been observed in Chinese women, suggesting that the combination of lowering $\mathrm{BP}$ and smoking cessation would contribute more to reducing $\mathrm{CHD}$ incidence than the effect of each change alone. ${ }^{94}$

\section{Obesity, diabetes mellitus, and dyslipidemia}

Obesity prevalence is rising among Canadian women, and increases with age. ${ }^{95}$ Rates of overweight and obesity among women in Canada vary significantly across ethnic groups, with lowest prevalence in South Asian and Southeast Asian women, and highest prevalence among black and off-reserve Indigenous women. ${ }^{96}$ Risks of CVD increase fourfold among women in the highest BMI category compared with women in the normal BMI range and, in the Framingham Heart Study, obesity increased the risk of CAD by $64 \%$. ${ }^{87}$ Obesity among women increases their risk of diabetes mellitus and women with diabetes have a threefold excess risk of fatal CAD compared with women without diabetes. ${ }^{87,97}$ Recognizing the importance of accumulated weight gain over a woman's lifespan, the recently published "Pregnancy and Maternal Obesity Part 2: Team Planning for Delivery and Postpartum Care" guideline summarizes that increased gestational weight gain and decreased postpregnancy weight loss increase a women's lifetime risks of obesity, and encourage achievement of healthy weight pre- and postpartum. ${ }^{98}$

Elevated total cholesterol, triglycerides, and LDL cholesterol levels, and decreased HDL cholesterol level are independent atherosclerotic risk factors for CVD. 99 In women, dyslipidemia contributes the highest proportion of the incidence of CVD (population attributable risk, 47.1\%) compared with all other traditional risk factors for CVD. ${ }^{87}$ These differences in lipid and glucose metabolism might be because of alterations in reproductive hormone levels during midlife (40-59 years). ${ }^{100,101}$ Among women, CRP is recognized as a strong CVD risk factor; indeed, screening of CRP among women aged 60 years and older has been recommended. ${ }^{102-104}$ Specifically among women, CRP might be a stronger predictor of future CVD than LDL cholesterol levels, and CRP and LDL are reported to identify different groups of women at higher risk of CVD. ${ }^{102,103} \mathrm{Lp}(\mathrm{a})$ remains a controversial and unfolding genetic risk factor in the development of CV and calcific aortic valve diseases. ${ }^{105,106}$ Uncertainty remains as to whether elevated $\mathrm{Lp}(\mathrm{a})$ is associated with the development of preeclampsia during pregnancy. ${ }^{107}$ Very high $\mathrm{Lp}(\mathrm{a})$ values have been deemed an independent risk factor in women for $\mathrm{MI}$ and in recurrent CHD events for postmenopausal women. ${ }^{108,109}$ In other studies, elevated $\mathrm{Lp}(\mathrm{a})$ increases CVD risk in women only when paired with high total cholesterol and/or elevated LDL cholesterol, and/or apolipoprotein B. ${ }^{110-113}$ Despite a similar recommended approach to treatment of dyslipidemia, many studies have shown that women are less likely to be prescribed lipid-lowering therapies or to achieve recommended cholesterol goals when treated compared with men's outcomes. ${ }^{90}$ This lack of adherence to treatment guidelines and failure to obtain recommended treatment goals contributes to women's poorer outcomes; moreover, this disparate treatment enhances the perception of bias in treating women with known cardiac risk factors and/or manifest CVD. ${ }^{90}$

\section{Physical activity and diet}

Across all ages and all times of the day, Canadian women are less physically active than men and report less time spent in moderate-to-vigorous and light physical activity, and greater time spent in sedentary activities, ${ }^{114,115}$ which are well established risk factors for CVD. ${ }^{116,117}$ Further, physical fitness might play a more significant role in limiting CVD development among women. ${ }^{18,119}$ Data from the Nurses Health Study showed that diets high in red and processed meats, high-fat dairy products, fried foods, salt, refined grains, and sugar increased heart disease risk among women, ${ }^{120}$ whereas adherence to a low-risk lifestyle, defined as not smoking, BMI $<25$, exercise $\geq 30$ minutes per day, and top $40 \%$ of the Alternate Mediterranean Diet Score (emphasizing high intake of vegetables, fruits, nuts, legumes, whole grains, fish, and moderate intake of alcohol) was associated with a lower risk of CHD and sudden cardiac death in women. ${ }^{121} \mathrm{It}$ is more than 20 years now that these health behaviour approaches were initially proposed as an effective strategy for the prevention of CHD and sudden cardiac death in women.

\section{Family history}

It is recommended that all individuals, including men and women, with a family history of premature CVD should be targeted for CV risk reduction interventions. Family history of CVD is an independent risk factor for premature CHD and is defined as patients having a first-degree relative with $\mathrm{CHD}$ at age younger than 55 years for men and/or younger than 65 years for women. Although it has been shown that women with a low Framingham Risk Score and a family history of premature $\mathrm{CHD}$ have a high prevalence of subclinical coronary atherosclerosis, ${ }^{122}$ the widely used American College of Cardiology/American Heart Association Atherosclerotic Cardiovascular Disease Risk Estimator, ${ }^{123}$ developed with pooled cohort equations from several large cohort studies of white and black men and women and which has largely supplanted the Framingham Risk Score, includes gender, age, BP, tobacco use, cholesterol, race, and diabetes status, but does not include family history. 


\section{Emerging Novel CV Risk Factors and Their Effect on Women}

\section{Autoimmune rheumatic diseases}

Systemic inflammation characterizes autoimmune rheumatic diseases (ARDs), including rheumatoid arthritis (RA) and systemic lupus erythematosus, which affect $8 \%$ of the population, of whom most (approximately 80\%) are women. ${ }^{124} \mathrm{CV}$ morbidity and mortality risks are greater for those with ARDs compared with the general population and with those with CAD. ${ }^{125,126} \mathrm{RA}$ is often considered a $\mathrm{CV}$ risk equivalent to diabetes in terms of endothelial damage ${ }^{125,127}$ and clinical atherosclerosis, ${ }^{128}$ with increased risk for heart failure and sudden cardiac arrest. ${ }^{124,126}$ In addition to atherosclerotic $\mathrm{CAD}$ and related complications, ARDs are associated with inflammatory complications of the myocardium, pericardium, valves, and vasculature and/or conduction system. ${ }^{128}$ CVD manifestations have also been described in patients with Sjögren syndrome, a rheumatic autoimmune disease that primarily affects women in midlife and might occur alone or in association with other autoimmune diseases, most commonly lupus and RA. ${ }^{129}$

The effect of ARDs on CV risk and CVD manifestations in women include: premature development of CAD 10 years earlier than age- and sex-matched controls ${ }^{128}$; increased risk of accelerated atherosclerosis with silent clinical presentation leading to heart failure ${ }^{124}$; up to $70 \%$ increased risk of $\mathrm{MI}^{130}$; $50 \%$ increased relative risk of recurrent ischemic events after percutaneous coronary interventions ${ }^{131,132}$; and worse healthrelated quality of life compared with healthy populations. ${ }^{133}$ Additionally, MetS is more prevalent in women of reproductive age with systemic lupus erythematosus. ${ }^{134}$ Awareness of the association between ARDs and CVD in women supports the importance of aggressive treatment with diseasemodifying antirheumatic drugs (to reduce systemic inflammation), management of CVD risk factors, and careful monitoring for manifestations of CVD.

Interplay of ARD symptoms and treatment in CVD diagnosis and risk. $A R D s$ can present with symptoms that are difficult to differentiate from the clinical symptoms of CVD: chest, jaw and neck, shoulder, and back pain, fatigue, and dyspnea. These symptoms are often misinterpreted by practitioners, and women themselves, as being attributed to an ARD, thereby increasing the potential risk for adverse cardiac events. ${ }^{135}$ Women with ARDs also present with other comorbid conditions, including depression, ${ }^{136}$ which might also affect CVD risk. Beyond atherosclerotic or inflammatory $\mathrm{CAD}$ and/or spasm, systemic inflammation in ARDs might cause myopericarditis, microvascular disease, vasculitis, valvular heart disease, and heart failure with preserved ejection fraction due to myocardial fibrotic changes.

RA-specific risk calculators using an empiric correction factor have not been successful in accurate prediction of CVD risk in patients with $\mathrm{RA}^{137}$; however, a recently developed tool evaluated in a population of $>30,000 \mathrm{RA}$ patients $(78 \%$ female), using clinical data and a multibiomarker disease activity score was shown to have good predictive accuracy, with a net reclassification index of 0.19 (95\% confidence interval, $0.10-0.27$; ) and C-index of $0.715 .{ }^{138}$ Importantly, despite
ARDs predominantly occurring in women, men are often treated more intensively than women and women experience longer delays in referral to specialist care than men. ${ }^{13}$

Summary. ARDs primarily affect women, and systemic inflammation associated with ARDs increases the risk of premature atherosclerotic CVD in addition to disorders of the myopericardium, valves, and conduction system. Cardiac symptoms can be misinterpreted as being related to an ARD, or can be absent, despite underlying disease; therefore, careful clinical assessments, including attention to $\mathrm{CV}$ risk factors, and early specialist referral as indicated for symptomatology indicative of disease, is recommended.

\section{Depression}

Depression is a disorder that ranges from a mild downturn in mood in reaction to everyday life events, to a genetically predisposed, biochemically-mediated severe disorder that can render the person unable to function, become psychotic, or suicidal. ${ }^{140}$ Symptoms might commonly include low mood, loss of interest, sleep impairment, appetite disturbance, concentration and memory difficulties, with occasional progression to an inability to function at home, work, or in the community. ${ }^{140}$ Depression can be clinically assessed, diagnosed, and classified by using the Diagnostic and Statistical Manual of Mental Disorders, Fifth Revision ${ }^{140}$ or International Classification of Diseases, 10 th Revision ${ }^{141}$ criteria. Several clinician or self-administered validated depression scales (Beck Depression Inventory-II ${ }^{142}$; Hospital Anxiety and Depression Scale ${ }^{143,144}$; Hamilton Depression Rating Scale ${ }^{145}$; Geriatric Depression Scale ${ }^{146}$; Patient Health Questionnaire-9 ${ }^{147}$; Cardiac Depression Scale ${ }^{148}$ ) are frequently used to assess depressive symptoms. In the general population, the prevalence of major depression is 1.7- to 2.0-fold higher in women $(5.5 \%)$ than in men $(3.2 \%){ }^{149}$ This is thought to be related to hormonal, biological, and psychosocial factors. ${ }^{149-152}$

Depression and CVD risk. For women, in particular, having a depression history is increasingly seen to be associated with CVD development. ${ }^{152,153}$ In one study, depressed women had a risk ratio of CVD development of 1.73 compared with nondepressed women. ${ }^{154}$ Depression has been reported to increase a woman's risk for adverse cardiac events by $50 \%-70 \% .{ }^{155}$ In the National Health and Nutrition Examination Survey III longitudinal study of adults aged younger than 40 years, women with a history of depression or suicide attempts had greater risk of developing CVD or ischemic heart disease than their male counterparts. ${ }^{156}$ Similarly, young women (48\%) have been reported to have a higher rate of long-term depression/depressive symptoms than men $(24 \%)$ at the time of MI. ${ }^{157}$ For postmenopausal women without previously diagnosed CHD, depressive symptoms have been associated with fatal CHD. ${ }^{158}$

Several sex- and gender-related explanations have been proposed for the apparent correlation between depression and CVD in women, including biological and behavioural factors, as well as socioeconomic and psychosocial stressors and vulnerabilities. ${ }^{152}$ For example, women are more likely to be physically inactive, ${ }^{159}$ and to experience lower levels of control at work and lower earnings, work overload due to additional 
housework and child care, single parenthood resulting in increased financial strain, loss of spouse in older age, and subsequent decrease in financial resources, and additional caregiving roles (eg, older parents). ${ }^{152}$ Additionally, for men and women, the CVD-depression relationship is increasingly seen as being bidirectional (depression leads to CVD and CVD to depression). ${ }^{152,153}$ In this regard, after a cardiac diagnosis, individuals have a higher incidence of depression than is found in the general population. ${ }^{153}$ Rates of depression after a cardiac diagnosis can be up to twice as high for women compared with men. ${ }^{152,160,161}$ Women diagnosed with a cardiac condition before the age of 60 years might be at particularly high risk for depression after their diagnosis, with rates substantially higher than in their male counterparts (39\% vs $22 \%) .{ }^{160}$

Quality of life. Women and men who experience depression after a cardiac diagnosis have a poorer quality of life than their nondepressed counterparts. ${ }^{153,162}$ This includes having a lower rate of return to work and a higher frequency of quitting work. ${ }^{163,164}$ Depressed cardiac patients have an overall worse medical prognosis, and have been reported to be rehospitalized sooner, with more frequent and longer hospitalizations. ${ }^{165}$ Post-MI depression, specifically, is associated with a 1.6- to 2.7-fold increase in the risk of adverse outcomes, including all-cause mortality, cardiac mortality, and cardiac morbidity within 2 years of diagnosis. ${ }^{166}$ One-year mortality after MI is higher for depressed individuals than for nondepressed individuals, in women $(8.3 \%$ vs $2.7 \%)$ and men $(7.0 \%$ vs $2.4 \%){ }^{167}$

Health outcomes and quality of life for depressed women with a cardiac history are worse than for depressed men and nondepressed women. After coronary artery bypass surgery, women with a history of depression experience inferior improvement in functional status 6 months postsurgery compared with nondepressed women and depressed men. ${ }^{168}$ Depressed women with low social integration are at higher risk of recurrent cardiac events compared with nondepressed socially integrated women. ${ }^{169}$ Outpatient women with chronic heart failure report lower self-perceived quality of life and higher depression rates compared with their male counterparts (64\% vs $44 \%$, respectively). ${ }^{170}$

Treatment of depression in primary and secondary prevention of CVD. Treating depression before the development of $\mathrm{CHD}$ has been shown to reduce the long-term absolute risk of serious CV events (MI or stroke) by $19 \% .{ }^{171}$ Although there is no direct evidence that screening for depression leads to improved outcomes in CV populations, depression has been linked with increased morbidity and mortality, poorer risk factor modification, lower rates of cardiac rehabilitation, and reduced quality of life. ${ }^{172-174}$ Therefore, the American Heart Association 2008 advisory on depression and CHD emphasized the importance of assessing depression in cardiac patients with the goal of targeting those most in need of treatment and support services. ${ }^{195}$ Jha et al. published a State-of-the-Art Review of screening and management of depression in patients with CVD to reinforce screening and best practices in medicine. ${ }^{176}$ It is recommended that screening for depressive symptoms with referral to interdisciplinary follow-up be completed with all newly diagnosed cardiac patients ${ }^{174,175}$ and that psychological supports be integrated into cardiac rehabilitation programs to improve depression outcomes. ${ }^{177}$

\section{Kidney disease}

Globally, chronic kidney disease (CKD) is more prevalent in women compared with men. ${ }^{178,179}$ There is a strong inverse relationship between level of kidney function and CV risk, and not only is the slope of the risk relationship steeper for women, but increased CV risk is shown earlier in the CKD disease course. ${ }^{180}$ Highlighting the importance of addressing $\mathrm{CKD}$ as a CVD risk factor, the 2015 Global Burden of Disease study estimated that 19 million disability-adjusted life-years, 18 million years of life, and 1.2 million deaths lost from CVD were directly attributable to reduced kidney function. ${ }^{181}$

Sex differences. Women have lower absolute glomerular filtration rates and renin-angiotensin system activity compared with men. ${ }^{182}$ Endogenous estrogen is associated with lower $\mathrm{BP}$ in women, ${ }^{69}$ though the effects of exogenous estrogen on kidney function, BP, and CV outcomes is less clear. ${ }^{183}$ Pregnancy complications such as gestational hypertension, GDM, and preeclampsia increase risk of CKD progression. ${ }^{184}$ Women have slower age-related loss of kidney function compared with men, likely because of sex differences, including less age-related renal nitric oxide dependence, but also gender-related factors such as greater adherence to kidneyrelated dietary restrictions in women. ${ }^{185,186}$ Parental history of $\mathrm{CVD}$ is a stronger risk factor in women compared with men for CKD progression. ${ }^{187}$

Most formulae to estimate kidney function are on the basis of serum creatinine, which in turn is influenced by factors such as muscle mass and protein intake. Muscle mass is less in women and creatinine-based formulae incorporate sex as a variable to estimate glomerular filtration rate ${ }^{188}$ and the risk of progression to kidney failure requiring dialysis or transplantation. ${ }^{189}$ Angiotensin-converting enzyme inhibitors and angiotensin receptor blockers in the treatment of hypertension might be less effective in women. ${ }^{190}$ In contrast to the general population, definitions of CKD-associated anemia are not sexspecific, which might lead to overestimation and overtreatment of anemia in women, a concern because erythropoiesis-stimulating agents carry some CV risk. ${ }^{191}$ In addition, women are less likely to receive arteriovenous fistulae for hemodialysis, ${ }^{192}$ and predialysis fistula creation attempts might be associated with a lower risk of sudden death and CV mortality. ${ }^{193}$ Women receiving dialysis have a similar mortality rate as age-matched men receiving dialysis, ${ }^{178}$ however, overestimation of dialysis adequacy has been reported to be due to overestimation of lean body mass in women, and higher dialysis doses have been associated with lower mortality among women but not men. ${ }^{194}$

Gender differences. From a gender perspective, women have slower loss of kidney function and are more likely to choose conservative care; women are less likely to initiate dialysis or receive a kidney transplantation. ${ }^{193}$ Living kidney donation is more common in women. ${ }^{195}$ Whether kidney donation 
increases CV risk remains under study ${ }^{196,197}$; however, among women of reproductive age, living kidney donors have increased rates of gestational hypertension and preeclampsia. $^{198}$

\section{Breast cancer therapies}

Breast cancer is the most common malignancy among women worldwide ${ }^{199}$ and it is estimated that $1.0 \%$ of the female Canadian population are survivors of breast cancer diagnosed within the past 15 years. ${ }^{200}$ As a result of significant improvements in screening and treatment, breast cancer mortality rates in Canada have had a steady decline of nearly $50 \%$ over the past 4 decades. ${ }^{201}$ With improvements in breast cancer-specific survival, CVD has emerged as an important competing risk in this population. ${ }^{202}$ Women with a personal history of breast cancer are at greater risk of dying from CVD than women without breast cancer, and for older women (older than 65 years) with a history of breast cancer, CVD is the leading cause of death. ${ }^{202,203}$

CVD risk and breast cancer therapies. Among women with a history of breast cancer, the balance of $\mathrm{CV}$ health with mortality can be influenced by a number of risk and protective factors that begin before diagnosis and extend to the posttreatment survivorship period, but active breast cancer treatment likely has the largest effect. ${ }^{204} \mathrm{CV}$ risks that might predate cancer diagnosis include older age, presence of traditional CV risk factors, and inflammation, whereas potential prediagnosis protective factors include lifelong non-smoking, regular physical activity, a healthy diet, and healthy body weight. A number of therapies used to treat breast cancer including anthracycline-based chemotherapy regimens, trastuzumab targeted therapy, and radiation therapy (especially for left-sided breast cancer) can cause cardiac and potentially vascular toxicity and dysfunction. ${ }^{205}$ Initial presentation of $\mathrm{CV}$ toxicity varies widely with individual treatment types, doses, and combinations, but can eventually manifest as heart failure, ischemic heart disease, and ultimately CVD-related death. $^{206}$

Health behaviour changes after breast cancer diagnosis. "Lifestyle" toxicity (ie, the worsening of health behaviours including physical activity and cardiorespiratory fitness, diet, body weight, stress) is a less recognized, but equally as common consequence of breast cancer therapy that contributes to CVD risk in this population. ${ }^{207}$ Potential protective factors during breast cancer therapy include maintenance or improvement of healthy lifestyle behaviours and prophylactic heart failure medications. ${ }^{208,209}$ After completion of treatment, practicing healthy lifestyle behaviours continues to be a key protective factor. The potential for chemotherapy-induced early menopause among women who were premenopausal at diagnosis (approximately 20\% in developed countries) is an additional important $\mathrm{CV}$ risk that should be considered in the post-treatment setting. ${ }^{210}$

\section{Sex-Based Pharmacology of CV Drugs}

Women and men have differences in pharmacokinetics of absorption, distribution, metabolism, and excretion of drugs, as well as pharmacodynamics of receptor binding, postreceptor effects, and chemical interactions of drugs. ${ }^{211}$ Many factors contribute to observed sex differences in CVD drug pharmacology. For example, if a drug is given transdermally, the dose received by a woman might be lower than that received by a man due to higher subcutaneous fat content in women. ${ }^{212}$ Similarly, differences in levels of gastric enzymes and transporter proteins between men and women cause differences in drug absorption. Drug distribution is affected by numerous parameters that differ between men and women, including BMI, body fat, plasma volume, and body water. ${ }^{213}$ However, sex differences in pharmacokinetics might be associated with adverse drug reactions in women because of higher blood concentrations and longer elimination times, rather than simply explained by differences in BMI. ${ }^{211}$

Many uncertainties regarding sex differences in CVD drug pharmacology are attributed to lack of data because of the under-representation of women in randomized clinical drug trials, a recurring issue that affects women in all aspects of CVD: diagnosis, acute treatment, short- and long-term pharmaceutical treatment, and prognosis. ${ }^{214}$ Trial exclusion criteria often explicitly list women of reproductive age in the exclusion criteria because of the potential for congenital malformations and litigation concerns. Furthermore, there were concerns that fluctuations in hormonal levels during the menstrual cycle could confound interpretation of drug pharmacokinetics. ${ }^{215}$ Although the US Food and Drug Administration and Health Canada regulations have advanced the inclusion of women and the analyses of sex differences in drug and device treatment responses, women's participation in clinical trials has improved in some, but not in all CVD areas. In their 2018 review of the participation of women in clinical trials of CV drugs, Scott et al. reported that although women were well represented in trials of drugs for hypertension and atrial fibrillation, representation of women in trials for heart failure, CAD, and acute coronary syndromes fell well below the participation to prevalence ratio deemed appropriate. ${ }^{214}$ Interestingly, the authors did not find evidence to support the concept that the inclusion or exclusion criteria were responsible for the under-representation of women in CVD trials, but rather postulated that low enrollment might be because gender-based issues limiting participation including familial responsibilities, cultural and socio-economic barriers, difficulty accessing the study site, and concerns about study risks.

Because of the increasing focus on precision medicine, the consideration of the patients' sex in clinical decision-making including the choice of diagnostic testing, medications, and other treatments is imperative. ${ }^{216}$ Many medications are metabolized differently in women compared with men because of differences in body size and distribution volumes, sex hormone levels, activity of enzymes, and effects of routes of excretion on sex-specific responses to drugs. ${ }^{217}$ At a minimum, there is a strong need for pharmaceutical trialists to report data disaggregated according to sex, even if underpowered, to enable subsequent pooling of sex-specific data during meta-analysis.

\section{Conclusions}

As shown in Figure 2, CVD risks can vary across a woman's lifespan, depending on her biologic stage (ie, puberty, 


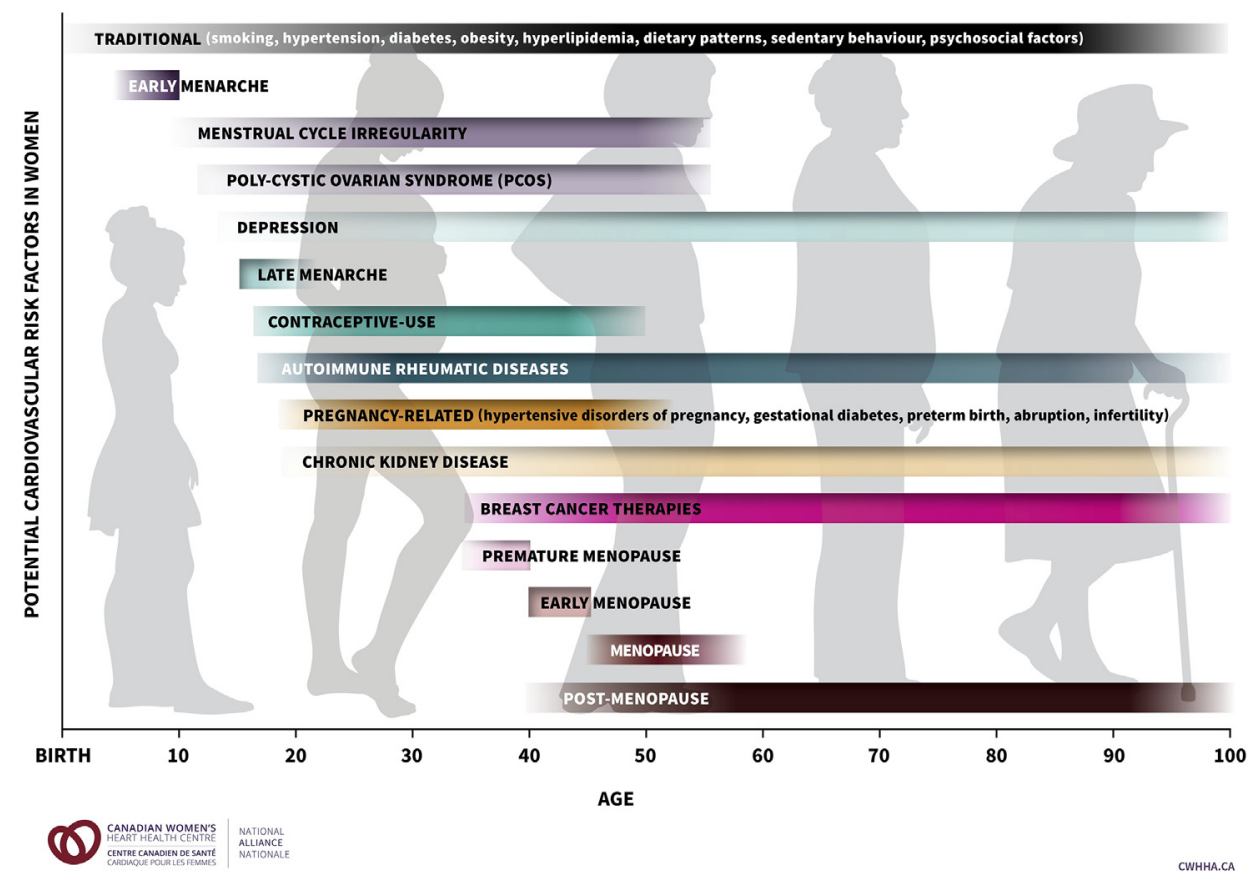

Figure 2. The average age of onset and average length of exposure to sex-unique and traditional factors that contribute to increased cardiovascular risk across a woman's lifespan.

pregnancy, and menopause). Similarly, differential CV risks are associated with traditional atherosclerotic risk factors as well as autoimmune and depressive disorders, which are more commonly found in women. Clinicians must consider sexspecific manifestations of comorbid disease processes, including ARDs, breast cancer, and kidney disease, on CV risks. Further, treatments are affected through sex-specific biological differences in metabolism of CVD drug and/or device therapies. All of these underlying medical factors and treatment-related issues need to be approached through the lens of sex and gender to improve CVD outcomes in women.

\section{Acknowledgements}

The authors gratefully acknowledge Lisa Comber for her ongoing coordination of this Atlas. A special thanks goes to Alexa Desjarlais from the University of Calgary and Manu Sandhu and Angela Poitras from the University of Ottawa Heart Institute for their graphic design of the central chapter illustration. Thanks to Manu Sandhu for graphic design of Figure 2. This article has been submitted on behalf of the CWHHA, a pan-Canadian network of approximately 100 clinicians, scientists, allied health professionals, program administrators, and patient partners, whose aim is to develop and disseminate evidence-informed strategies to transform clinical practice and enhance collaborative action on women's CV health in Canada. The CWHHA is powered by the Canadian Women's Heart Health Centre at the University of Ottawa Heart Institute.

\section{Funding Sources}

Supported by the University of Ottawa Heart Institute Foundation.

\section{Disclosures}

S.L.M. is a member of the Novo Nordisk SOUL trial steering committee. A.L.E.L. has received grants from Astra Zeneca. The remaining authors have no conflicts of interest to disclose.

\section{References}

1. Norris CM, Yip CYY, Nerenberg KA, et al. State of the science in women's cardiovascular disease: a Canadian perspective on the influence of sex and gender. J Am Heart Assoc 2020;9:e015634.

2. Jaffer S, Foulds HJA, Parry M, et al. The Canadian Women's Heart Health Alliance ATLAS on the epidemiology, diagnosis, and management of cardiovascular disease in women chapter 2: scope of the problem. CJC Open 2020;3:1-11.

3. Norris CM, Yip CYY, Nerenberg KA, et al. Introducing the Canadian Women's Heart Health Alliance ATLAS on the epidemiology, diagnosis, and management of cardiovascular diseases in women. CJC Open 2020;2:145-50.

4. Lee JJ, Cook-Wiens G, Johnson BD, et al. Age at menarche and risk of cardiovascular disease outcomes: findings from the National Heart Lung and Blood Institute-sponsored women's ischemia syndrome evaluation. J Am Heart Assoc 2019;8:e12406.

5. Rostami Dovom M, Ramezani Tehrani F, Djalalinia S, Cheraghi L, Behboudi Gandavani S, Azizi F. Menstrual cycle irregularity and metabolic disorders: a population-based prospective study. PLoS One 2016;11:e0168402.

6. Zheng Y, Zhang G, Chen Z, Zeng Q. Association between age at menarche and cardiovascular disease risk factors in China: a large population-based investigation. Cardiorenal Med 2016;6:307-16. 
7. Al-Sahab B, Ardern CI, Hamadeh MJ, Tamim H. Age at menarche in Canada: results from the National Longitudinal Survey of Children \& Youth. BMC Public Health 2010;10:736.

8. Freedman DS, Khan LK, Serdula MK, Dietz WH, Srinivasan SR, Berenson GS. Relation of age at menarche to race, time period, and anthropometric dimensions: the Bogalusa Heart Study. Pediatrics 2002;110:e43.

9. Herman-Giddens ME, Slora EJ, Wasserman RC, et al. Secondary sexual characteristics and menses in young girls seen in office practice: a study from the Pediatric Research in Office Settings network. Pediatrics 1997;99:505-12.

10. Wu T, Mendola P, Buck GM. Ethnic differences in the presence of secondary sex characteristics and menarche among US girls: the Third National Health and Nutrition Examination Survey, 1988-1994. Pediatrics 2002;110:752-7.

11. Harris MA, Prior JC, Koehoorn M. Age at menarche in the Canadian population: secular trends and relationship to adulthood BMI. J Adolesc Health 2008;43:548-54.

12. Onland-Moret NC, Peeters PH, van Gils CH, et al. Age at menarche in relation to adult height: the EPIC study. Am J Epidemiol 2005;162: $623-32$.

13. Luijken J, van der Schouw YT, Mensink D, Onland-Moret NC. Association between age at menarche and cardiovascular disease: a systematic review on risk and potential mechanisms. Maturitas 2017;104: 96-116.

14. Schisterman EF, Mumford SL, Sjaarda LA. Failure to consider the menstrual cycle phase may cause misinterpretation of clinical and research findings of cardiometabolic biomarkers in premenopausal women. Epidemiol Rev 2014;36:71-82.

15. McKinley PS, King AR, Shapiro PA, et al. The impact of menstrual cycle phase on cardiac autonomic regulation. Psychophysiology 2009;46:904-11.

16. Roos-Hesselink JW, Cornette J, Sliwa K, Pieper PG, Veldtman GR, Johnson MR. Contraception and cardiovascular disease. Eur Heart J 2015;36:1728-34. 1734a-b.

17. Kaminski P, Szpotanska-Sikorska M, Wielgos M. Cardiovascular risk and the use of oral contraceptives. Neuro Endocrinol Lett 2013;34: 587-9.

18. Roach RE, Helmerhorst FM, Lijfering WM, Stijnen T, Algra A, Dekkers OM. Combined oral contraceptives: the risk of myocardial infarction and ischemic stroke. Cochrane Database Syst Rev 2015;8: CD011054.

19. World Health Organization. Medical eligibility criteria for contraceptive use. Available at: https://www.who.int/reproductivehealth/publications/ family_planning/MEC-5/en/. Accessed June 22, 2020.

20. Adeniji AA, Essah PA, Nestler JE, Cheang KI. Metabolic effects of a commonly used combined hormonal oral contraceptive in women with and without polycystic ovary syndrome. J Womens Health (Larchmt) 2016;25:638-45.

21. Amiri M, Nahidi F, Bidhendi-Yarandi R, Khalili D, Tohidi M, Ramezani Tehrani F. A comparison of the effects of oral contraceptives on the clinical and biochemical manifestations of polycystic ovary syndrome: a crossover randomized controlled trial. Hum Reprod 2020;35: $175-86$.

22. Hunter S, Robson SC. Adaptation of the maternal heart in pregnancy. Br Heart J 1992;68:540-3.
23. Sanghavi M, Rutherford JD. Cardiovascular physiology of pregnancy. Circulation 2014;130:1003-8.

24. Lisonkova S, Bartholomew S, Rouleau J, Liu S, Liston RM, Joseph KS. Temporal trends in maternal mortality in Canada I: estimates based on vital statistics data. J Obstet Gynaecol Can 2011;33:1011-9.

25. Pfaller B, Sathananthan G, Grewal J, et al. Preventing complications in pregnant women with cardiac disease. J Am Coll Cardiol 2020;75: $1443-52$

26. California Maternal Quality Care Collaborative. Improving Health Care Response to Cardiovascular Disease in Pregnancy and Postpartum. Available at: https://www.cmqcc.org/resource/improving-health-careresponse-cardiovascular-disease-pregnancy-and-postpartum. Accessed October 30, 2020.

27. Silversides CK, Grewal J, Mason J, et al. Pregnancy outcomes in women with heart disease: the CARPREG II study. J Am Coll Cardiol 2018;71: 2419-30.

28. Regitz-Zagrosek V, Blomstrom Lundqvist C, Borghi C, et al. ESC guidelines on the management of cardiovascular diseases during pregnancy: the Task Force on the Management of Cardiovascular Diseases during Pregnancy of the European Society of Cardiology (ESC). Eur Heart J 2011;32:3147-97.

29. Grandi SM, Filion KB, Yoon S, et al. Cardiovascular disease-related morbidity and mortality in women with a history of pregnancy complications. Circulation 2019;139:1069-79.

30. Davis MB, Walsh MN. Cardio-obstetrics team-based care to improve maternal outcomes. Circ Cardiovasc Qual Outcomes 2019;12:e005417.

31. Butalia S, Audibert F, Côté AM, et al. Hypertension Canada's 2018 guidelines for the management of hypertension in pregnancy. Can J Cardiol 2018;34:526-31.

32. Henderson JT, Witlock EP, Rowland MG. Low-dose aspirin for prevention of morbidity and mortality from preeclampsia: a systematic evidence review for the U.S. Preventive Services Task Force. Ann Intern Med 2014;160:695-703.

33. Regitz-Zagrosek V, Roos-Hesselink JW, Bauersachs J, et al. 2018 ESC guidelines for the management of cardiovascular diseases during pregnancy. Eur Heart J 2018;39:3165-241.

34. Dumesic DA, Oberfield SE, Stener-Victorin E, Marshall JC, Laven JS, Legro RS. Scientific statement on the diagnostic criteria, epidemiology, pathophysiology, and molecular genetics of polycystic ovary syndrome. Endocr Rev 2015;36:487-525.

35. March WA, Moore VM, Willson KJ, Phillips DI, Norman RJ, Davies MJ. The prevalence of polycystic ovary syndrome in a community sample assessed under contrasting diagnostic criteria. Hum Reprod 2010;25:544-51.

36. Ding T, Hardiman PJ, Petersen I, Wang FF, Qu F, Baio G. The prevalence of polycystic ovary syndrome in reproductive-aged women of different ethnicity: a systematic review and meta-analysis. Oncotarget 2017;8:96351-8.

37. Lim SS, Davies MJ, Norman RJ, Moran LJ. Overweight, obesity and central obesity in women with polycystic ovary syndrome: a systematic review and meta-analysis. Hum Reprod Update 2012;18:618-37.

38. Kowalska I, Straczkowski M, Nikolajuk A, et al. Serum visfatin in relation to insulin resistance and markers of hyperandrogenism in lean and obese women with polycystic ovary syndrome. Hum Reprod 2007;22:1824-9. 
39. Legro RS, Arslanian SA, Ehrmann DA, et al. Diagnosis and treatment of polycystic ovary syndrome: an Endocrine Society clinical practice guideline. J Clin Endocrinol Metab 2013;98:4565-92.

40. Lord J, Thomas R, Fox B, Acharya U, Wilkin T. The central issue? Visceral fat mass is a good marker of insulin resistance and metabolic disturbance in women with polycystic ovary syndrome. BJOG 2006;113:1203-9.

41. Nandi A, Chen Z, Patel R, Poretsky L. Polycystic ovary syndrome. Endocrinol Metab Clin North Am 2014;43:123-47.

42. Palomba S, Santagni S, Falbo A, La Sala GB. Complications and challenges associated with polycystic ovary syndrome: current perspectives. Int J Womens Health 2015;7:745-63.

43. Barry JA, Kuczmierczyk AR, Hardiman PJ. Anxiety and depression in polycystic ovary syndrome: a systematic review and meta-analysis. Hum Reprod 2011;26:2442-51.

44. Carmina E. Metabolic syndrome in polycystic ovary syndrome. Minerva Ginecol 2006;58:109-14.

45. Ehrmann DA, Liljenquist DR, Kasza K, Azziz R, Legro RS, Ghazzi MN. Prevalence and predictors of the metabolic syndrome in women with polycystic ovary syndrome. J Clin Endocrinol Metab 2006;91:48-53.

46. Wild RA, Bartholomew MJ. The influence of body weight on lipoprotein lipids in patients with polycystic ovary syndrome. Am J Obstet Gynecol 1988;159:423-7.

47. Wild RA, Painter PC, Coulson PB, Carruth KB, Ranney GB. Lipoprotein lipid concentrations and cardiovascular risk in women with polycystic ovary syndrome. J Clin Endocrinol Metab 1985;61:946-51.

48. Moran LJ, Misso ML, Wild RA, Norman RJ. Impaired glucose tolerance, type 2 diabetes and metabolic syndrome in polycystic ovary syndrome: a systematic review and meta-analysis. Hum Reprod Update 2010;16:347-63.

49. Tasali E, Van Cauter E, Ehrmann DA. Relationships between sleep disordered breathing and glucose metabolism in polycystic ovary syndrome. J Clin Endocrinol Metab 2006;91:36-42.

50. Vgontzas AN, Legro RS, Bixler EO, Grayev A, Kales A, Chrousos GP. Polycystic ovary syndrome is associated with obstructive sleep apnea and daytime sleepiness: role of insulin resistance. J Clin Endocrinol Metab 2001;86:517-20.

51. Armanini D, Bordin L, Dona G, et al. Polycystic ovary syndrome: implications of measurement of plasma aldosterone, renin activity and progesterone. Steroids 2012;77:655-8.

52. Osibogun O, Ogunmoroti O, Michos ED. Polycystic ovary syndrome and cardiometabolic risk: opportunities for cardiovascular disease prevention. Trends Cardiovasc Med 2020;30:399-404.

53. Teede HJ, Misso ML, Costello MF, et al. Recommendations from the international evidence-based guideline for the assessment and management of polycystic ovary syndrome. Hum Reprod 2018;33:1602-18.

54. Naderpoor N, Shorakae S, de Courten B, Misso ML, Moran LJ, Teede HJ. Metformin and lifestyle modification in polycystic ovary syndrome: systematic review and meta-analysis. Hum Reprod Update 2015;21:560-74.

55. Armanini D, Andrisani A, Bordin L, Sabbadin C. Spironolactone in the treatment of polycystic ovary syndrome. Expert Opin Pharmacother 2016;17:1713-5.
56. Baber RJ, Panay N, Fenton A. 2016 IMS recommendations on women's midlife health and menopause hormone therapy. Climacteric 2016;19:109-50.

57. Barrett-Connor E. Menopause, atherosclerosis, and coronary artery disease. Curr Opin Pharmacol 2013;13:186-91.

58. Tepper PG, Brooks MM, Randolph JF Jr, et al. Characterizing the trajectories of vasomotor symptoms across the menopausal transition. Menopause 2016;23:1067-74.

59. Zhu D, Chung HF, Dobson AJ, et al. Vasomotor menopausal symptoms and risk of cardiovascular disease: a pooled analysis of six prospective studies. Am J Obstet Gynecol 2020;223. 898.e1-16.

60. Lobo RA, Pickar JH, Stevenson JC, Mack WJ, Hodis HN. Back to the future: hormone replacement therapy as part of a prevention strategy for women at the onset of menopause. Atherosclerosis 2016;254:282-90.

61. Quinn MM, Cedars MI. Cardiovascular health and ovarian aging. Fertil Steril 2018;110:790-3.

62. Honigberg MC, Zekavat SM, Aragam K, et al. Association of premature natural and surgical menopause with incident cardiovascular disease. JAMA 2019;322:2411-21.

63. Honigberg MC, Zekavat SM, Niroula A, et al. Premature menopause, clonal hematopoiesis, and coronary artery disease in postmenopausal women. Circulation 2021;143:410-23.

64. The North American Menopause Society. The 2017 hormone therapy position statement of The North American Menopause Society. Menopause 2017;24:728-53.

65. Grundy SM, Stone NJ, Bailey AL, et al. 2018 AHA/ACC/AACVPR/ AAPA/ABC/ACPM/ADA/AGS/APhA/ASPC/NLA/PCNA guideline on the management of blood cholesterol: a report of the American College of Cardiology/American Heart Association Task Force on Clinical Practice Guidelines. Circulation 2019;139:e1082-143.

66. Barinas-Mitchell E, Duan C, Brooks M, et al. Cardiovascular disease risk factor burden during the menopause transition and late midlife subclinical vascular disease: does race/ethnicity matter? J Am Heart Assoc 2020;9:e013876.

67. Sowers M, Crawford S, Sternfeld B, et al. Menopause: biology and pathobiology. In: Menopause: Biology and Pathobiology. New York: Academic Press, 2000:175-88.

68. Miller VM, Harman SM. An update on hormone therapy in postmenopausal women: mini-review for the basic scientist. Am J Physiology Heart Circ Physiol 2017;313:H1013-21.

69. Morselli E, Santos RS, Criollo A, Nelson MD, Palmer BF, Clegg DJ. The effects of oestrogens and their receptors on cardiometabolic health. Nat Rev Endocrinol 2017;13:352-64.

70. El Khoudary SR, Aggarwal B, Beckie TM, et al. Menopause transition and cardiovascular disease risk: implications for timing of early prevention: a scientific statement from the American Heart Association. Circulation 2020;142:e506-32.

71. Lundberg G, Wu P, Wenger N. Menopausal hormone therapy: a comprehensive review. Curr Atheroscler Rep 2020;22:33.

72. Pinkerton JV. Hormone therapy for postmenopausal women. N Engl J Med 2020;382:446-55.

73. Boardman HM, Hartley L, Eisinga A, et al. Hormone therapy for preventing cardiovascular disease in post-menopausal women. Cochrane Database Syst Rev 2015;3:CD002229. 
74. Hodis HN, Mack WJ, Henderson VW, et al. Vascular effects of early versus late postmenopausal treatment with estradiol. N Engl J Med 2016;374:1221-31.

75. Hodis HN, Mack WJ, Shoupe D, et al. Methods and baseline cardiovascular data from the Early versus Late Intervention Trial with Estradiol testing the menopausal hormone timing hypothesis. Menopause 2015;22:391-401.

76. Hulley S, Grady D, Bush T, et al. Randomized trial of estrogen plus progestin for secondary prevention of coronary heart disease in postmenopausal women. JAMA 1998;280:605-13.

77. Manson JE, Chlebowski RT, Stefanick ML, et al. Menopausal hormone therapy and health outcomes during the intervention and extended poststopping phases of the Women's Health Initiative randomized trials. JAMA 2013;310:1353-68.

78. Marjoribanks J, Farquhar C, Roberts H, Lethaby A, Lee J. Long-term hormone therapy for perimenopausal and postmenopausal women. Cochrane Database Syst Rev 2017;1:CD004143.

79. Miller VM, Naftolin F, Asthana S, et al. The Kronos Early Estrogen Prevention Study (KEEPS): what have we learned? Menopause 2019;26:1071-84.

80. Rossouw JE, Anderson GL, Prentice RL, et al. Risks and benefits of estrogen plus progestin in healthy postmenopausal women: principal results From the Women's Health Initiative randomized controlled trial. JAMA 2002;288:321-33.

81. Schierbeck LL, Rejnmark L, Tofteng CL, et al. Effect of hormone replacement therapy on cardiovascular events in recently postmenopausal women: randomised trial. BMJ 2012;345:e6409.

82. Shaw LJ, Bairey Merz CN, Pepine CJ, et al. Insights from the NHLBIsponsored Women's Ischemia Syndrome Evaluation (WISE) study: part I: gender differences in traditional and novel risk factors, symptom evaluation, and gender-optimized diagnostic strategies. J Am Coll Cardiol 2006; 47 (3 suppl):S4-20.

83. EUGenMed Cardiovascular Clinical Study Group, Regitz-Zagrosek V, Oertelt-Prigione S, et al. Gender in cardiovascular diseases: impact on clinical manifestations, management, and outcomes. Eur Heart J 2015;37:24-34.

84. Zhao M, Woodward M, Vaartjes I, et al. Sex differences in cardiovascular medication prescription in primary care: a systematic review and meta-analysis. J Am Heart Assoc 2020;9:e014742.

85. Yusuf S, Hawken S, Ounpuu S, et al. Effect of potentially modifiable risk factors associated with myocardial infarction in 52 countries (the INTERHEART study): case-control study. Lancet 2004;364:937-52.

86. Mehta LS, Beckie TM, DeVon HA, et al. Acute myocardial infarction in women: a scientific statement from the American Heart Association. Circulation 2016;133:916-47.

87. Garcia M, Mulvagh SL, Merz CNB, Buring JE, Manson JE. Cardiovascular disease in women: clinical perspectives. Circ Res 2016;118: 1273-93.

88. Pimenta E. Hypertension in women. Hypertens Res 2012;35:148-52.

89. Ji H, Kim A, Ebinger JE, et al. Sex differences in blood pressure trajectories over the life course. JAMA Cardiol 2020;5:19-26.

90. McSweeney JC, Rosenfeld AG, Abel WM, et al. Preventing and experiencing ischemic heart disease as a woman: state of the science. Circulation 2016;133:1302-31.
91. Lloyd-Jones DM, Evans JC, Levy D. Hypertension in adults across the age spectrum: current outcomes and control in the community. JAMA 2005;294:466-72.

92. Ong KL, Tso AW, Lam KS, Cheung BM. Gender difference in blood pressure control and cardiovascular risk factors in Americans with diagnosed hypertension. Hypertension 2008;51:1142-8.

93. Roger VL, Go AS, Lloyd-Jones DM, et al. Heart disease and stroke statistics-2011 update: a report from the American Heart Association. Circulation 2011;123:e18-209.

94. Sun D, Cao J, Liu X, et al. Combined effects of smoking and systolic blood pressure on risk of coronary heart disease: a cohort study in Chinese women. J Womens Health (Larchmt) 2010;19:713-8.

95. Wharton S, Lau DCW, Vallis M, et al. Obesity in adults: a clinical practice guideline. CMAJ 2020;192:E875-91.

96. Valera B, Sohani Z, Rana A, Poirier P, Anand SS. The ethnoepidemiology of obesity. Can J Cardiol 2015;31:131-41.

97. Kautzky-Willer A, Harreiter J, Pacini G. Sex and gender differences in risk, pathophysiology and complications of type 2 diabetes mellitus. Endocr Rev 2016;37:278-316.

98. Maxwell C, Gaudet L, Cassir G, et al. Guideline no. 392-pregnancy and maternal obesity part 2: team planning for delivery and postpartum care. J Obstet Gynaecol Can 2019;41:1660-75.

99. Miller M. Dyslipidemia and cardiovascular risk: the importance of early prevention. QJM 2009;102:657-67.

100. Chia CW, Egan JM, Ferrucci L. Age-related changes in glucose metabolism, hyperglycemia, and cardiovascular risk. Circ Res 2018;123: 886-904.

101. Varlamov O, Bethea CL, Roberts CT Jr. Sex-specific differences in lipid and glucose metabolism. Front Endocrinol 2014;5:241.

102. Ridker PM. C-reactive protein. Circulation 2003;108:e81-5.

103. Salazar J, Martínez MS, Chávez M. C-reactive protein: clinical and epidemiological perspectives. Cardiol Res Pract 2014;2014:605810.

104. Strang F, Schunkert H. C-reactive protein and coronary heart disease: all said - is not it? Mediators Inflamm 2014;2014:757123.

105. Tsimikas S. A test in context: lipoprotein(a): diagnosis, prognosis, controversies, and emerging therapies. J Am Coll Cardiol 2017;69: 692-711.

106. Tsimikas S, Fazio S, Ferdinand KC, et al. NHLBI working group recommendations to reduce lipoprotein(a)-mediated risk of cardiovascular disease and aortic stenosis. J Am Coll Cardiol 2018;71:177-92.

107. Fanshawe AE, Ibrahim M. The current status of lipoprotein (a) in pregnancy: a literature review. J Cardiol 2013;61:99-106.

108. Kamstrup PR, Benn M, Tybjaerg-Hansen A, Nordestgaard BG. Extreme lipoprotein(a) levels and risk of myocardial infarction in the general population: the Copenhagen City Heart Study. Circulation 2008;117:176-84.

109. Shlipak MG, Simon JA, Vittinghoff E, et al. Estrogen and progestin, lipoprotein(a), and the risk of recurrent coronary heart disease events after menopause. JAMA 2000;283:1845-52.

110. Afshar M, Pilote L, Dufresne L, Engert JC, Thanassoulis G. Lipoprotein(a) interactions with low-density lipoprotein cholesterol and other cardiovascular risk factors in premature acute coronary syndrome (ACS). J Am Heart Assoc 2016;5:e003012.

111. Cook NR, Mora S, Ridker PM. Lipoprotein(a) and cardiovascular risk prediction among women. J Am Coll Cardiol 2018;72:287-96. 
112. Rosenson RS, Marcovina SM. Refining lipoprotein(a) associated cardiovascular risk in women. J Am Coll Cardiol 2018;72:297-9.

113. Suk Danik J, Rifai N, Buring JE, Ridker PM. Lipoprotein(a), measured with an assay independent of apolipoprotein(a) isoform size, and risk of future cardiovascular events among initially healthy women. JAMA 2006;296:1363-70

114. Colley RC, Michaud I, Garriguet D. Reallocating time between sleep, sedentary and active behaviours: associations with obesity and health in Canadian adults. Health Rep 2018;29:3-13.

115. Garriguet D, Colley RC. Daily patterns of physical activity among Canadians. Health Rep 2012;23:27-32.

116. Després JP. Physical activity, sedentary behaviours, and cardiovascular health: when will cardiorespiratory fitness become a vital sign? Can J Cardiol 2016;32:505-13.

117. Myers J, McAuley P, Lavie CJ, Despres JP, Arena R, Kokkinos P. Physical activity and cardiorespiratory fitness as major markers of cardiovascular risk: their independent and interwoven importance to health status. Prog Cardiovasc Dis 2015;57:306-14.

118. Chomistek AK, Chiuve SE, Eliassen AH, Mukamal KJ, Willett WC, Rimm EB. Healthy lifestyle in the primordial prevention of cardiovascular disease among young women. J Am Coll Cardiol 2015;65:43-51.

119. Juraschek SP, Blaha MJ, Whelton SP, et al. Physical fitness and hypertension in a population at risk for cardiovascular disease: the Henry Ford ExercIse Testing (FIT) Project. J Am Heart Assoc 2014;3: e001268.

120. Fung TT, Willett WC, Stampfer MJ, Manson JE, Hu FB. Dietary patterns and the risk of coronary heart disease in women. Arch Intern Med 2001;161:1857-62.

121. Stampfer MJ, Hu FB, Manson JE, Rimm EB, Willett WC. Primary prevention of coronary heart disease in women through diet and lifestyle. N Engl J Med 2000;343:16-22.

122. Michos ED, Vasamreddy CR, Becker DM, et al. Women with a low Framingham risk score and a family history of premature coronary heart disease have a high prevalence of subclinical coronary atherosclerosis. Am Heart J 2005;150:1276-81.

123. Goff DC Jr, Lloyd-Jones DM, Bennett G, et al. 2013 ACC/AHA guideline on the assessment of cardiovascular risk: a report of the American College of Cardiology/American Heart Association Task Force on Practice Guidelines. Circulation 2014;129(25 suppl 2): S49-73.

124. Mavrogeni SI, Markousis-Mavrogenis G, Koutsogeorgopoulou L, et al. Pathophysiology and imaging of heart failure in women with autoimmune rheumatic diseases. Heart Fail Rev 2019;24:489-98.

125. Agca R, Heslinga SC, van Halm VP, Nurmohamed MT. Atherosclerotic cardiovascular disease in patients with chronic inflammatory joint disorders. Heart 2016;102:790-5.

126. Mantel Ä, Holmqvist M, Jernberg T, Walllberg-Jonsson S, Askling J. Rheumatoid arthritis is associated with a more severe presentation of acute coronary syndrome and worse short-term outcome. Eur Heart ] 2015;36:3413-22.

127. Adlan AM, Paton JF, Lip GY, Kitas GD, Fisher JP. Increased sympathetic nerve activity and reduced cardiac baroreflex sensitivity in rheumatoid arthritis. J Physiol 2017;595:967-81.

128. Prasad M, Hermann J, Gabriel SE, et al. Cardiorheumatology: cardiac involvement in systemic rheumatic disease. Nat Rev Cardiol 2015;12: 168-76.
129. Wu XF, Huang JY, Chiou JY, Chen HH, Wei JCC, Dong LL. Increased risk of coronary heart disease among patients with primary Sjögren's syndrome: a nationwide population-based cohort study. Sci Rep 2018;8:2209.

130. Ogdie A, Yu Y, Haynes K, et al. Risk of major cardiovascular events in patients with psoriatic arthritis, psoriasis and rheumatoid arthritis: a population-based cohort study. Ann Rheum Dis 2015;74:326-32.

131. McCoy SS, Crowson CS, Maradit-Kremers H, et al. Longterm outcomes and treatment after myocardial infarction in patients with rheumatoid arthritis. J Rheumatol 2013;40:605-10.

132. Sintek MA, Sparrow CT, Mikuls TR, et al. Repeat revascularisation outcomes after percutaneous coronary intervention in patients with rheumatoid arthritis. Heart 2016;102:363-9.

133. Salaffi F, Carotti M, Gasparini S, Intorcia M, Grassi W. The healthrelated quality of life in rheumatoid arthritis, ankylosing spondylitis, and psoriatic arthritis: a comparison with a selected sample of healthy people. Health Qual Life Outcomes 2009;7:25.

134. Mok CC. Metabolic syndrome and systemic lupus erythematosus: the connection. Exp Rev Clin Immunol 2019;15:765-75.

135. Kurmann RD, Mankad R. Atherosclerotic heart disease in women with autoimmune rheumatologic inflammatory conditions. Can J Cardiol 2018;34:381-9.

136. Matcham F, Rayner L, Steer S, Hotopf M. The prevalence of depression in rheumatoid arthritis: a systematic review and meta-analysis. Rheumatology (Oxford) 2013;52:2136-48.

137. Crowson CS, Gabriel SE, Semb AG, et al. Rheumatoid arthritis-specific cardiovascular risk scores are not superior to general risk scores: a validation analysis of patients from seven countries. Rheumatology (Oxford) $2017 ; 56: 1102-10$.

138. Curtis JR, Xie F, Crowson CS, et al. Derivation and internal validation of a multi-biomarker-based cardiovascular disease risk prediction score for rheumatoid arthritis patients. Arthritis Res Ther 2020;22:282.

139. Favalli EG, Biggioggero M, Crotti C, Becciolini A, Raimondo MG, Meroni PL. Sex and management of rheumatoid arthritis. Clin Rev Allergy Immunol 2019;56:333-45.

140. Diagnostic and Statistical Manual of Mental Disorders, Fifth Revision (DSM-5). Arlington, VA: American Psychiatric Association, 2018.

141. ICD-10: International Classification of Diseases, 10th Revision. Geneva: World Health Organization, 2015.

142. Beck AT, Steer RA, Carbin MG. Psychometric properties of the Beck Depression Inventory: twenty-five years of evaluation. Clini Psychol Rev 1988;8:77-100.

143. Lemay KR, Tulloch HE, Pipe AL, Reed JL. Establishing the minimal clinically important difference for the hospital anxiety and depression scale in patients with cardiovascular disease. J Cardiopulm Rehabil Prev 2019;39:E6-11.

144. Snaith RP. The Hospital Anxiety and Depression Scale. Health Qual Life Outcomes 2003;1:29.

145. Hamilton M. A rating scale for depression. J Neurol Neurosurg Psychiatry 1960;23:56-62.

146. Yesavage JA, Brink TL, Rose TL, et al. Development and validation of a geriatric depression screening scale: a preliminary report. J Psychiatr Res $1982 ; 17: 37-49$.

147. Kroenke K, Spitzer RL, Williams JB. The PHQ-9: validity of a brief depression severity measure. J Gen Intern Med 2001;16:606-13. 
148. Hare DL, Davis CR. Cardiac Depression Scale: validation of a new depression scale for cardiac patients. J Psychosom Res 1996;40:379-86.

149. Albert PR. Why is depression more prevalent in women? J Psychiatry Neurosci 2015;40:219-21.

150. Finks SW. Cardiovascular Disease in Women. Pharmacotherapy SelfAssessment Program. 7th Ed. Lenexa, KS: American College of Clinical Pharmacy, 2010.

151. Keita GP. Psychosocial and cultural contributions to depression in women: considerations for women midlife and beyond. J Manag Care Pharm 2007;13(9 suppl A):S12-5.

152. Möller-Leimkühler AM. Higher comorbidity of depression and cardiovascular disease in women: a biopsychosocial perspective. World J Biol Psychiatry 2010;11:922-33.

153. Hare DL, Toukhsati SR, Johansson P, Jaarsma T. Depression and cardiovascular disease: a clinical review. Eur Heart J 2014;35:1365-72.

154. Ferketich AK, Schwartzbaum JA, Frid DJ, Moeschberger ML. Depression as an antecedent to heart disease among women and men in the NHANES I study. National Health and Nutrition Examination Survey. Arch Intern Med 2000;160:1261-8.

155. Vaccarino V, Badimon L, Corti R, et al. Ischaemic heart disease in women: are there sex differences in pathophysiology and risk factors?: Position Paper from the Working Group on Coronary Pathophysiology and Microcirculation of the European Society of Cardiology. Cardiovasc Res 2010;90:9-17.

156. Shah AJ, Veledar E, Hong Y, Bremner JD, Vaccarino V. Depression and history of attempted suicide as risk factors for heart disease mortality in young individuals. Arch Gen Psychiatry 2011;68:1135-42.

157. Smolderen KG, Strait KM, Dreyer RP, et al. Depressive symptoms in younger women and men with acute myocardial infarction: insights from the VIRGO study. J Am Heart Assoc 2015;4:e001424.

158. Wassertheil-Smoller S, Shumaker S, Ockene J, et al. Depression and cardiovascular sequelae in postmenopausal women: the Women's Health Initiative (WHI). Arch Intern Med 2004;164:289-98.

159. Guthold R, Stevens GA, Riley LM, Bull FC. Worldwide trends in insufficient physical activity from 2001 to 2016: a pooled analysis of 358 population-based surveys with 1.9 million participants. Lancet Glob Health 2018;6:e1077-86.

160. Mallik S, Spertus JA, Reid KJ, et al. Depressive symptoms after acute myocardial infarction: evidence for highest rates in younger women. Arch Intern Med 2006;166:876-83.

161. Shanmugasegaram S, Russell KL, Kovacs AH, Stewart DE, Grace SL. Gender and sex differences in prevalence of major depression in coronary artery disease patients: a meta-analysis. Maturitas 2012;73:305-11.

162. Müller-Tasch T, Peters-Klimm F, Schellberg D, et al. Depression is a major determinant of quality of life in patients with chronic systolic heart failure in general practice. J Card Fail 2007;13:818-24.

163. de Jonge P, Zuidersma M, Bültmann U. The presence of a depressive episode predicts lower return to work rate after myocardial infarction. Gen Hosp Psychiatry 2014;36:363-7.

164. Smedegaard L, Numé AK, Charlot M, Kragholm K, Gislason G, Hansen PR. Return to work and risk of subsequent detachment from employment after myocardial infarction: insights from Danish nationwide registries. J Am Heart Assoc 2017;6:e006486.

165. Reese RL, Freedland KE, Steinmeyer BC, Rich MW, Rackley JW, Carney RM. Depression and rehospitalization following acute myocardial infarction. Circ Cardiovasc Qual Outcomes 2011;4:626-33.
166. Meijer A, Conradi HJ, Bos EH, Thombs BD, van Melle JP, de Jonge P. Prognostic association of depression following myocardial infarction with mortality and cardiovascular events: a meta-analysis of 25 years of research. Gen Hosp Psychiatry 2011;33:203-16.

167. Frasure-Smith N, Lespérance F, Juneau M, Talajic M, Bourassa MG. Gender, depression, and one-year prognosis after myocardial infarction. Psychosom Med 1999;61:26-37.

168. Mallik S, Krumholz HM, Lin ZQ, et al. Patients with depressive symptoms have lower health status benefits after coronary artery bypass surgery. Circulation 2005;111:271-7.

169. Horsten M, Mittleman MA, Wamala SP, Schenck-Gustafsson K, OrthGomér K. Depressive symptoms and lack of social integration in relation to prognosis of CHD in middle-aged women. The Stockholm Female Coronary Risk Study. Eur Heart J 2000;21:1072-80.

170. Gottlieb SS, Khatta M, Friedmann E, et al. The influence of age, gender, and race on the prevalence of depression in heart failure patients. J Am Coll Cardiol 2004;43:1542-9.

171. Stewart JC, Perkins AJ, Callahan CM. Effect of collaborative care for depression on risk of cardiovascular events: data from the IMPACT randomized controlled trial. Psychosom Med 2014;76:29-37.

172. Cocchio S, Baldovin T, Furlan P, et al. Is depression a real risk factor for acute myocardial infarction mortality? A retrospective cohort study. BMC Psychiatry 2019;19:122.

173. Langvik E, Nordahl HM. Anhedonic depression, history of depression, and anxiety as gender-specific risk factors of myocardial infarction in healthy men and women: the HUNT study. Health Psychol Open 2014;1. 2055102914557658.

174. Nieuwsma JA, Williams JW Jr, Namdari N, et al. Diagnostic accuracy of screening tests and treatment for post-acute coronary syndrome depression: a systematic review. Ann Intern Med 2017;167:725-35.

175. Lichtman JH, Bigger JT Jr, Blumenthal JA, et al. Depression and coronary heart disease: recommendations for screening, referral, and treatment: a science advisory from the American Heart Association Prevention Committee of the Council on Cardiovascular Nursing, Council on Clinical Cardiology, Council on Epidemiology and Prevention, and Interdisciplinary Council on Quality of Care and Outcomes Research: endorsed by the American Psychiatric Association. Circulation 2008;118:1768-75.

176. Jha MK, Qamar A, Vaduganathan M, Charney DS, Murrough JW. Screening and management of depression in patients with cardiovascular disease: JACC State-of-the-Art Review. J Am Coll Cardiol 2019;73: $1827-45$.

177. Pogosova N, Saner H, Pedersen SS, et al. Psychosocial aspects in cardiac rehabilitation: from theory to practice. A position paper from the Cardiac Rehabilitation Section of the European Association of Cardiovascular Prevention and Rehabilitation of the European Society of Cardiology. Eur J Prev Cardiol 2015;22:1290-306.

178. Carrero JJ, Hecking M, Chesnaye NC, Jager KJ. Sex and gender disparities in the epidemiology and outcomes of chronic kidney disease. Nat Rev Nephrol 2018;14:151-64.

179. Mills KT, Xu Y, Zhang W, et al. A systematic analysis of worldwide population-based data on the global burden of chronic kidney disease in 2010. Kidney Int 2015;88:950-7.

180. Nitsch D, Grams M, Sang Y, et al. Associations of estimated glomerular filtration rate and albuminuria with mortality and renal failure by sex: a meta-analysis. BMJ 2013;346:f324. 
181. Luyckx VA, Tonelli M, Stanifer JW. The global burden of kidney disease and the sustainable development goals. Bull World Health Organ 2018;96. 414-22d.

182. Miller JA, Anacta LA, Cattran DC. Impact of gender on the renal response to angiotensin II. Kidney Int 1999;55:278-85.

183. Barton M, Meyer MR. Postmenopausal hypertension. Hypertension 2009;54:11-8.

184. Dehmer EW, Phadnis MA, Gunderson EP, et al. Association between gestational diabetes and incident maternal CKD: the Coronary Artery Risk Development in Young Adults (CARDIA) study. Am J Kidney Dis 2018;71:112-22.

185. Ahmed SB, Fisher ND, Hollenberg NK. Gender and the renal nitric oxide synthase system in healthy humans. Clin J Am Soc Nephrol 2007;2:926-31.

186. Halbesma N, Brantsma AH, Bakker SJL, et al. Gender differences in predictors of the decline of renal function in the general population. Kidney Int 2008;74:505-12.

187. Huang X, Sui X, Ruiz JR, et al. Parental history of premature cardiovascular disease, estimated GFR, and rate of estimated GFR decline: results from the Aerobics Center Longitudinal Study. Am J Kidney Dis 2015;65:692-700.

188. Levey AS, Stevens LA, Schmid CH, et al. A new equation to estimate glomerular filtration rate. Ann Intern Med 2009;150:604-12.

189. Tangri N, Grams ME, Levey AS, et al. Multinational assessment of accuracy of equations for predicting risk of kidney failure: a metaanalysis. JAMA 2016;315:164-74.

190. Rabi DM, Khan N, Vallee M, Hladunewich MA, Tobe SW, Pilote L. Reporting on sex-based analysis in clinical trials of angiotensin-converting enzyme inhibitor and angiotensin receptor blocker efficacy. Can J Cardiol 2008;24:491-6.

191. Del Vecchio L, Locatelli F. An overview on safety issues related to erythropoiesis-stimulating agents for the treatment of anaemia in patients with chronic kidney disease. Expert Opin Drug Saf 2016;15: 1021-30.

192. Miller CD, Robbin ML, Allon M. Gender differences in outcomes of arteriovenous fistulas in hemodialysis patients. Kidney Int 2003;63: 346-52.

193. Quinn RR, Oliver MJ, Devoe D, et al. The effect of predialysis fistula attempt on risk of all-cause and access-related death. J Am Soc Nephrol 2017;28:613-20.

194. Eknoyan G, Beck GJ, Cheung AK, et al. Effect of dialysis dose and membrane flux in maintenance hemodialysis. N Engl J Med 2002;347: 2010-9.

195. Piccoli GB, Alrukhaimi M, Liu ZH, et al. What we do and do not know about women and kidney diseases; questions unanswered and answers unquestioned: reflection on World Kidney Day and International Woman's Day. BMC Nephrol 2018;19:66.

196. Garg AX, Meirambayeva A, Huang A, et al. Cardiovascular disease in kidney donors: matched cohort study. BMJ 2012;344:e1203.

197. Mjøen G, Hallan S, Hartmann A, et al. Long-term risks for kidney donors. Kidney Int 2014;86:162-7.

198. Garg AX, McArthur E, Lentine KL. Gestational hypertension and preeclampsia in living kidney donors. N Engl J Med 2015;372: $1469-70$.

199. Bray F, Ferlay J, Soerjomataram I, Siegel RL, Torre LA, Jemal A. Global cancer statistics 2018: GLOBOCAN estimates of incidence and mortality worldwide for 36 cancers in 185 countries. CA Cancer J Clin 2018;68:394-424.

200. Marrett LD, Prithwish D, Aioria P, Dryer D. Cancer in Canada 2008. CMAJ 2008;179:1163-70.

201. Brenner DR, Weir HK, Demers AA, et al. Projected estimates of cancer in Canada in 2020. CMAJ 2020;192:E199-205.

202. Gernaat SAM, Ho PJ, Rijnberg N, et al. Risk of death from cardiovascular disease following breast cancer: a systematic review. Breast Cancer Res Treat 2017;164:537-55.

203. Patnaik JL, Byers T, DiGuiseppi C, Dabelea D, Denberg TD. Cardiovascular disease competes with breast cancer as the leading cause of death for older females diagnosed with breast cancer: a retrospective cohort study. Breast Cancer Res 2011;13:R64.

204. Kirkham AA, Beaudry RI, Paterson DI, Mackey JR, Haykowsky MJ. Curing breast cancer and killing the heart: a novel model to explain elevated cardiovascular disease and mortality risk among women with early stage breast cancer. Prog Cardiovasc Dis 2019;62:116-26.

205. Perez IE, Taveras Alam S, Hernandez GA, Sancassani R. Cancer therapy-related cardiac dysfunction: an overview for the clinician. Clin Med Insights Cardiol 2019;13. 1179546819866445.

206. Virani SA, Dent S, Brezden-Masley C, et al. Canadian Cardiovascular Society guidelines for evaluation and management of cardiovascular complications of cancer therapy. Can J Cardiol 2016;32:831-41.

207. Bodai BI, Tuso P. Breast cancer survivorship: a comprehensive review of long-term medical issues and lifestyle recommendations. Perm J 2015;19:48-79.

208. Ligibel JA, Basen-Engquist K, Bea JW. Weight management and physical activity for breast cancer prevention and control. Am Soc Clin Oncol Educ Book 2019;39:e22-33.

209. Valachis A, Nilsson C. Cardiac risk in the treatment of breast cancer: assessment and management. Breast Cancer (Dove Med Press) 2015;7: $21-35$.

210. Ghiasvand R, Adami HO, Harirchi I, Akrami R, Zendehdel K. Higher incidence of premenopausal breast cancer in less developed countries; myth or truth? BMC Cancer 2014;14:343.

211. Zucker I, Prendergast BJ. Sex differences in pharmacokinetics predict adverse drug reactions in women. Biol Sex Diff 2020;11:32.

212. Soldin OP, Mattison DR. Sex differences in pharmacokinetics and pharmacodynamics. Clin Pharmacokinet 2009;48:143-57.

213. Soldin OP, Chung SH, Mattison DR. Sex differences in drug disposition. J Biomed Biotechnol 2011;2011:187103.

214. Scott PE, Unger EF, Jenkins MR, et al. Participation of women in clinical trials supporting FDA approval of cardiovascular drugs. J Am Coll Cardiol 2018;71:1960-9.

215. Liu KA, Mager NA. Women's involvement in clinical trials: historical perspective and future implications. Pharm Pract (Granada) 2016;14: 708.

216. Miller VM, Kararigas G, Seeland U, et al. Integrating topics of sex and gender into medical curricula-lessons from the international community. Biol Sex Differ 2016;7(suppl 1):44.

217. Garcia M, Miller VM, Gulati M, et al. Focused cardiovascular care for women: the need and role in clinical practice. Mayo Clin Proc 2016;91: 226-40.

218. Curtis KM, Tepper NK, Jatlaoui TC, et al. U.S. Medical Eligibility Criteria for Contraceptive Use. Available at: https://www.cdc.gov/ 
mmwr/volumes/65/rr/rr6503a1.htm?s_cid=rr6503a1_w. Accessed August 20, 2021.

219. Black A, Guilbert E, Costescu D, et al. No. 329-Canadian contraception consensus part 4 of 4 chapter 9: combined hormonal contraception. J Obstet Gynaecol Can 2017;39:229-268.e225.

220. Moussa HN, Rajapreyar I. ACOG practice bulletin no. 212: pregnancy and heart disease. Obstet Gynecol 2019;133:e320-56.

221. Chapter 2 Cardiovascular Disease. J Obstet Gynaecol Can 2014;36: S16-22.

222. ACOG Committee Opinion No. 565: hormone therapy and heart disease. Obstet Gynecol 2013;121:1407-10.

223. The Canadian Rheumatology Association. Chronic Pain, Diclofenac and Cardiovascular Risk: Management Algorithm. Available at: https:// rheum.ca/resources/publications/. Accessed August 20, 2021.
224. The American College of Rheumatology. Clinical Practice Guidelines. Available at: https://www.rheumatology.org/Practice-Quality/ClinicalSupport/Clinical-Practice-Guidelines. Accessed August 19, 2021.

225. Stevens PE, Levin A. Evaluation and management of chronic kidney disease: synopsis of the kidney disease: improving global outcomes 2012 clinical practice guideline. Ann Intern Med 2013;158:825-30.

226. Plana JC, Galderisi M, Barac A, et al. Expert consensus for multimodality imaging evaluation of adult patients during and after cancer therapy: a report from the American Society of Echocardiography and the European Association of Cardiovascular Imaging. J Am Soc Echocardiogr 2014;27:911-39.

227. Rabi DM, McBrien KA, Sapir-Pichhadze R, et al. Hypertension Canada's 2020 comprehensive guidelines for the prevention, diagnosis, risk assessment, and treatment of hypertension in adults and children. Can J Cardiol 2020;36:596-624. 